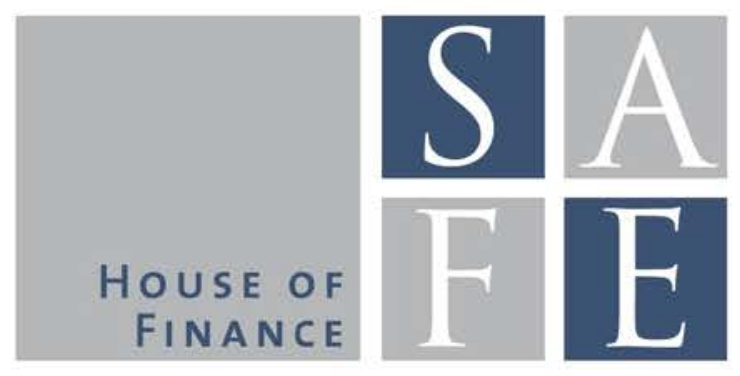

WORKING PAPER SERIES

Florian Deuflhard

\title{
Quantifying Inertia in Retail Deposit Markets
}

SAFE Working Paper No. 223

\section{SAFE I Sustainable Architecture for Finance in Europe}

A cooperation of the Center for Financial Studies and Goethe University Frankfurt 


\title{
Quantifying Inertia in Retail Deposit Markets
}

\author{
By Florian Deuflhard*
}

Draft: March 2018

This paper investigates inertia within and across banks in retail deposit markets using detailed panel data on consumer choices and account characteristics. In a structural choice model, I find that costs of inertia are around one third higher for switching accounts across compared to switching within banks. Observable proxies of bank-level switching costs (number and type of additional financial products) explain most of this cost premium, while online banking usage reduces inertia. Consistent with theory, I provide evidence that banks incorporate inertia in their pricing as older accounts pay lower rates than comparable newer accounts. Counterfactual policies reducing inertia shift market share to more competitive smaller banks, but only eliminating inertia within banks already results in high potential gains in consumer surplus. This suggests that facilitating bank switching alone might be insufficient to improve consumer choices.

\footnotetext{
* Department of Economics, Goethe University Frankfurt. Email: florian.deuflhard@hof.uni-frankfurt.de. I especially thank my advisors Roman Inderst and Christine Zulehner for their guidance on this project. I also thank Ben Handel, Gregory Crawford, Francesco Decarolis, Liran Einav, Tülin Erdem, Dimitris Georgarakos, Jozsef Molnar, Helena Perrone, Rafael Repullo, Michelle Sovinsky, Konrad Stahl, as well as participants of the 2016 EARIE (Lisbon), the 2016 CEPR Applied IO school (London), the 2016 Bank of England, FCA, and CMA Research Seminars (London), and the 2015 Summer School 'Empirical Analysis of Markets with Incomplete Information' (University of Mannheim) for helpful comments and discussions. I am grateful to a major Dutch bank for providing interest rate data on savings accounts in the Netherlands, to CentERdata for providing additional information on financial product holdings and bank relationships of DNB survey participants, to SpaarInformatie for providing data on restrictions of Dutch savings accounts, as well as to Thomas Mosk for providing bank branch data for the Netherlands.
} 


\section{Introduction}

In retail banking markets, consumers often stick to their choices in the presence of better alternatives. This inertia is widely believed to negatively impact competition by modifying incumbent pricing strategies and restricting large-scale entry $!^{1}$ Low switching rates in deposit markets have, thus, been an ongoing concern of regulatory authorities. In 2009, the Dutch central bank noted that:2

...by offering higher deposit interest rates, new entrants might be able to attract quantities of savings that are relevant to them, but this has as yet not resulted in large shifts in the savings market as a whole. [...] the majority of Dutch savers seem thereby relatively interest rate-indifferent.

Measuring inertia and its determinants is important for the design of effective policies to improve consumer choices. Two main approaches to study inertia in financial markets exist. The industrial organization literature, on the one hand, has employed discrete choice models to quantify inertia separately from individual preferences over differentiated financial service providers but neglected the multiplicative nature of benefits in financial markets $3^{3}$ The household finance literature, on the other hand, has studied deviations from optimal behavior in financial product choice highlighting the role of wealth to overcome inertia as a fixed cost of taking an action but ignored other sources of preferences resulting in choice persistence 4

This paper bridges both literatures. I develop a structural choice model that quantifies inertia within and across banks, volume-dependent price sensitivities, and heterogeneous consumer preferences. I use these estimates to evaluate the impact of counterfactual policies of likely regulatory concern. I estimate the model using detailed panel data on savings account choices of Dutch consumers to measure inertia within and across banks and link it to observable consumer characteristics and related choices. My findings indicate that removing inertia within banks alone results in around one third of the surplus gains from an overall elimination of inertia for the average consumer.

My primary data source is the DNB household survey from 2005 to 2008 . The data contain information on all savings accounts held by consumers including bank

1 Farrell and Klemperer (2007) survey the theoretical literature on switching costs concluding that on balance switching costs tend to raise prices, in particular, in richer models. Inertia might, in addition, result in inefficiently large small-scale entry if incumbents cannot price discriminate between new and old customers.

${ }^{2}$ See DNB (2009). See also the more recent retail banking market investigation by the Financial Conduct Authority in the UK (FCA (2015)), which concludes that consumers do not sufficiently switch savings accounts despite high potential benefits. The Competition and Markets Authority (CMA (2016)) recently reached similar conclusions in a large market investigation for personal current accounts.

${ }^{3}$ See, e.g., Handel (2013), Polyakova (2016), Ho, Hogan and Morton (2017), Honka (2014), Honka, Hortaçsu and Vitorino (2017)

${ }^{4}$ See, e.g., Madrian and Shea (2001), Brunnermeier and Nagel (2008), Guiso, Sodini et al. (2013), Andersen et al. (2018) 
and account names as well as account volume. In addition, I observe information on consumer demographics, online banking usage, and bank names of additional financial products such as checking accounts and mortgages. I complement the survey with data from a comparison website over the same time period containing information on interest rates for all Dutch banks which for some accounts vary with invested volume. The data also contain information on the existence of additional account restrictions. Last, I add data on the location of bank branches covering all Dutch provinces during the sample period.

Several key features of the Dutch deposit market make it well suited for the research question at hand. First, there are potential gains from switching across banks due to a set of aggressively pricing smaller banks. Second, there are gains from switching within banks as banks offer multiple differentiated accounts. Third, the relative attractiveness of the available accounts shifted over time due to differential pass-through of rising monetary policy rates and the regular introduction of new accounts. Despite the changing choice environment, account switching within and across banks remained at $6 \%$ to $8 \%$ per year. While this could suggest the presence of inertia, the observed patterns are also consistent with persistent consumer preferences.

I first estimate two reduced-form specifications to analyze determinants of account switching. In a pooled linear probability model including a rich set of demographics and other controls, I find that measures of the scope of the bank relationship (holding a salary account at the main bank) as well as account- and bank-level switching costs (number of savings accounts and bank relationships) substantially reduce account switching, while frequent online banking users are more likely to switch. In a fixed effects specification, I find that within-individual variation in interest rate benefits and account volume are important trigger factors inducing switching. In summary, these results suggest several potential determinants of inertia and highlight the importance of monetary benefits for explaining switching behavior in deposit markets.

To measure these effects and analyze the impact of counterfactual policies, I develop a structural choice model that jointly quantifies inertia within and across banks, volumedependent price sensitivities, and heterogeneous preferences. I construct depositors' unobservable choice sets depending on their invested volume under a full information assumption. In the model, consumers maximize their utility over the available accounts given their volume conditional on their price sensitivity and tastes for account and bank attributes. While several economic explanations might generate inertia, I model inertia as an implied monetary premium on the previous account and bank choice relative to alternative options $5^{5}$ As price sensitivities depend on individual account volume, the

\footnotetext{
${ }^{5}$ This compares to the modeling approach in the literature on the structural estimation of switching costs. Alternative explanations might imply different choice models, while in this work I analyze the contribution of
} 
model recovers a full inertia distribution. I allow for heterogeneous inertia and account preferences as well as tastes for local branch presence. To handle the initial conditions problem in my dynamic specification, I adjust an approach by Wooldridge (2005) to the mixed logit model used in this paper ${ }^{6}$ In addition, I exploit the presence of depositors choosing without inertia in any given year to further separate inertia from other sources of unobserved preferences. Last, I account for the potential endogeneity of interest rates using a control function approach.

The choice model estimates reveal large and heterogeneous inertia both in absolute monetary terms and relative to volume. Inertia costs within banks are $€ 360(3.2 \%)$ annually for the average consumer with a standard deviation of $€ 562$ (2.3\%), while average inertia costs across banks are $€ 464(4.1 \%)$ with a standard deviation of $€ 720$ $(3.0 \%)$. The substantial heterogeneity is mainly driven by different monetary switching benefits of consumers. Depositors with smaller account holdings have high relative but low absolute inertia, which reverses for wealthier consumers. Due to the right-skewed distribution of volume, this results in around $50 \%$ lower absolute inertia for the median compared to the average consumer. Measures of bank-level switching costs and the scope of the bank relationship mainly explain the additional inertia costs for switching across banks, while online banking usage reduces overall inertia. The remaining unexplained inertia, in particular within banks, suggests that unmeasured behavioral explanations might also be important drivers of inertia. 7 My preference estimates confirm the importance of local branch presence and reveal some meaningful heterogeneity in account preferences with respect to consumer demographics. I provide several robustness checks to show that my results are stable across different specifications.

On the supply side, I provide reduced-form evidence that banks price discriminate based on inertia once accounts reach a certain maturation point consistent with an 'invest'- and 'harvest'-dynamic as described in Klemperer (1995) 8 Older accounts pay progressively lower rates than newer accounts across all volume categories.9 In addition, larger banks offer lower interest rates on average conditional on account restrictions and account age consistent with the idea that banks with a larger customer base should have stronger incentives to exploit inertia.

proxies for potential micro foundations to the estimated inertia costs.

6 Wooldridge (2005) proposes to control for persistent unobserved preferences correlated with the initial condition by modeling inertia conditional on the initial values observed in the data. Originally shown for binary and ordered choice models, I adjust the approach to the unordered multinomial case with more than two products.

${ }^{7}$ The theoretical literature offers a number of potential micro foundations for inertia including search, switching, or learning costs, as well as implicit psychological costs such as inattention or procrastination. See Farrell and Klemperer (2007) and Thaler and Sunstein (2008) for surveys on this matter.

${ }^{\circ}$ As described in Klemperer (1995), new products will first be marketed to a higher share of incoming customers. As the product matures over time, the share of locked-in customers gradually increases, thus, increasing the pricing power of firms for older products.

${ }^{9}$ For example, five years old accounts pay on average $0.64 \%$ and seven years old accounts $1.1 \%$ less than just introduced accounts for a volume of $€ 10,000$. 
In two counterfactual exercises, I study how potential policy interventions impact market outcomes in a partial equilibrium framework holding prices fixed. In the first counterfactual, I find that reducing inertia shifts market share from larger to more competitive smaller banks resulting in large potential gains in consumer surplus. In a second counterfactual, I study how the composition of inertia impacts consumer choices. I find that allowing for costless optimization within banks, holding inertia across banks fixed, leads to gains in consumer surplus amounting to almost a third of the gains from an overall elimination of inertia.

Related literature. This paper contributes to three main strands of literature. First, I provide a new framework to study inertia in financial product choice which complements existing approaches in household finance 10 Several studies show that households respond slowly or stay inactive to financial incentives related to their retirement savings (Madrian and Shea (2001)), portfolio investing (e.g., Bilias, Georgarakos and Haliassos (2010); Brunnermeier and Nagel (2008)) or debt refinancing (Woodward and Hall (2012); Andersen et al. (2018)). Similar to recent work by Gambacorta et al. (2017), I take an approach inspired by the Industrial Organization literature and model individual preferences in characteristics space. In line with Andersen et al. (2018), I show that monetary switching benefits are an important determinant of the implied inertia distribution. Within the household finance literature, my paper is the first to quantify inertia separately from other sources of preferences and study the impact of counterfactual policies improving individual choices on market structure.

Second, the paper adds to a growing literature quantifying consumer inertia and related phenomena, in particular in financial markets 11 Recent examples using micro panel data on consumer choices include Handel (2013), Polyakova (2016) or Ho, Hogan and Morton (2017) in health insurance markets. While, as in these prior studies, I do not distinguish between distinct sources of inertia, I exploit the multi-product nature of the banking industry to structurally separate inertia within and across banks to shed light on underlying choice frictions. This contrasts with recent work by Honka, Hortaçsu and Vitorino (2017) who structurally disentangle awareness, consideration, and choice stage using cross-sectional data on consumer bank choices 12 While my inertia estimates implicitly capture costs incurred on all stages, information on account

\footnotetext{
${ }^{10}$ See Campbell (2006) and Guiso, Sodini et al. (2013) for excellent reviews.

${ }^{11} \mathrm{~A}$ number of studies exist outside of financial markets. Examples include Goettler and Clay (2011) for grocery delivery plans, Sudhir and Yang (2014) for rental cars, Grubb, Osborne et al. (2015) for cellular-service plans, or Crawford, Tosini and Waehrer (2011) for the UK voice market. Shum (2004), Dubé, Hitsch and Rossi (2009, 2010), and Pavlidis and Ellickson (2017) are examples of a related literature in marketing studying the effect of brand loyalty or state dependence.

${ }_{12}$ Honka (2014) and Kiss (2017) separate switching costs from search costs or inattention, respectively, in auto insurance markets. Heiss et al. (2016) separate switching costs and inattention in Medicare Part D. Luco (2016) analyzes the relative importance of decision and enrollment costs in the market for pension funds.
} 
choices allows me to analyze inertia within bank as well 13 In addition, I can account for unobserved persistent preferences due to the availability of panel data. Last, allowing for multiplicative switching benefits recovers a full inertia distribution depending on account volume in contrast to average effects.

Last, this study relates to reduced-form work providing indirect evidence of switching costs in deposit markets. Sharpe (1997), Hannan and Adams (2011), and CarboValverde, Hannan and Rodriguez-Fernandez (2011) find that areas with higher inmigration, and, thus, a supposedly higher share of people choosing without default option, offer higher deposit rates on average. Several authors analyze instead determinants of switching banks using survey data and find that household relocation, service, and price factors (Kiser (2002)), proxies for switching costs (Brown, Guin and Morkoetter (2013)), but also education and financial literacy (Brunetti, Ciciretti and Djordjevic (2016)) matter for the propensity to switch. I provide new reduced-form evidence that monetary switching benefits and online banking usage are important determinants of the decision to switch. Moreover, I explicitly quantify inertia and individual preferences in a structural framework and study the effect of counterfactual policies improving individual choices.

The rest of the paper is organized as follows. Section II describes the Dutch deposit market. Section III presents the data and summary statistics. Section IV provides preliminary evidence of inertia. Section $\mathrm{V}$ introduces the empirical framework, while Section VI presents the structural choice model estimates, robustness checks, and evidence on determinants of inertia. Section VII analyzes implications for bank pricing. Section VIII performs counterfactual simulations. Section IX concludes.

\section{The Dutch deposit market}

The Dutch central bank distinguishes between three main types of deposit accounts: While checking accounts are used for transactional purposes, savings accounts and fixedterm deposits receive interest with the former being redeemable any time and the latter being held over an agreed maturity. In this study, I focus on savings accounts which constitute the most important form of savings for Dutch households ${ }^{14}$ As savings accounts are fully flexible, this allows to meaningfully compare prices in the market by homogenizing the maturity dimension. One concern with this approach is that savings accounts at large banks are only available in bundles with checking accounts, while smaller banks offer 'savings accounts only'-services. In practice, however, consumers can hold a current account at one of the big banks, while holding a separate savings

\footnotetext{
13 Honka, Hortaçsu and Vitorino (2017) assume that consumers choose the most popular account offered by a bank despite the existence of account menus due to the lack of data on account choices of consumers.

${ }^{14}$ See, e.g., DNB (2015).
} 
account free of charge at a small bank. As a result, the Dutch competition authority does not perceive bundling as a switching barrier 15

Almost all banks offer multiple differentiated types of savings accounts which can be roughly partitioned across two dimensions. First, accounts are either internet managed or not. Internet accounts are fully managed online by the depositor and offer only limited banking services. In addition, accounts can be restricted or not. These restrictions include, for example, balance requirements, withdrawal limitations, or the requirement of a salary account at the same bank. While these account characteristics remain stable over time, interest rates fluctuate in response to changing monetary policy rates. The left panel of Table A1 shows that this within-bank differentiation can result in quite large account menus which vary in size depending on the bank. For example, in 2005, ABN Amro offers 8, while Rabobank offers only 3 accounts. The variation over time shows that banks regularly enter and exit accounts.

The Dutch deposit market is considered one of the most concentrated in the EU area ${ }^{16}$ The right panel of Table $\mathrm{A} 1$ shows that the three largest banks (Rabobank, ABN Amro, ING Bank) share a stable market share of around $75 \%$ followed by SNS Bank and Fortis Bank with around 5\% market share between 2005 and 2008. The difficulty of new entrants to gain significant market share in combination with low switching rates has prompted concerns both by the Dutch central bank and the competition authority. A survey conducted by the latter revealed that $50 \%$ of consumers above 18 had never switched their savings account, the majority of which were customers of large banks ${ }^{17}$

The dominance of the large banks is also reflected in the distribution of branches across the twelve Dutch provinces. To illustrate, Figure 1 shows the geographic variation of the branch share for the largest four banks in 2005. Not surprisingly, Rabobank as a cooperative bank with a traditionally large branch network has by far the highest coverage with branch shares above 50\% in most provinces. ABN Amro, ING Bank, and SNS Bank follow with high distance in descending order. While the differential availability of branches, thus, likely impacts bank choice in the Netherlands, ATM withdrawals are usually free of charge for owners of a Dutch debit card both nationally as well as in other countries of the European Union.

${ }^{15}$ See PWC (2015), a recent study commissioned by the Financial conduct authority (FCA) as well as Cruijsen, Diepstraten et al. (2017), who argue that checking and savings accounts in the Netherlands should be evaluated separately due to significantly differing switching rates. Similarly, Honka, Hortaçsu and Vitorino (2017) also do not simultaneously model the choice of multiple account types

${ }^{16}$ See, e.g., DNB (2015).

${ }^{17}$ See, DNB (2009) and ACM 2014). 


\section{Data and Environment}

\section{A. Data description}

My main data source is the DNB Household Survey (DHS) from 2005 to 2008. The DHS is an annually conducted survey of around 2,000 Dutch households containing extensive information on demographic characteristics, asset and debt holdings, housing, work, health and income, as well as economic and psychological concepts. The survey is representative of the Dutch population and is conducted via the Internet 18 One key feature of the survey is that it asks detailed information on all savings accounts held by each household member, including bank and account name, as well as invested volume on each account 19 The data also contain information on bank names of other financial products such as checking accounts and mortgages as well as online banking usage ${ }^{20}$ All asset amounts and bank information are reported as of December 31 of the year preceding the interviews.

I complement this data set with additional information on savings account characteristics from two sources. I use data on annual interest rates for savings accounts of all Dutch banks from December 2004 to December 2007 provided by a major Dutch financial institution. The data set covers in total 40 banks offering 140 savings accounts. For each savings account, it contains the weekly interest rate for eleven different amount brackets ranging from $€ 0-€ 1,000$ to $€ 45,000$ or more 21 In addition, I use data on the existence of various savings account restrictions provided by the Dutch Internet comparison website 'SpaarInformatie'. Apart from internet accounts, the information from the comparison website allows to distinguish in total six main restrictions such as balance requirements or withdrawal limitations ${ }^{22}$

\footnotetext{
${ }^{18}$ The survey provides equipment to households without Internet access in order to compensate for this form of bias. See Teppa and Vis (2012) for a detailed description of the DHS.

${ }^{19}$ In the regular panel, participants are provided with a list of seven possible answers when asked at which bank they hold each of their savings accounts: ABN Amro, Postbank, Rabobank, ING, Fortis, SNS Bank, and 'Other'. In case participants indicate ownership in the category 'Other', they are further asked to provide the name of the bank. This latter information along with account names is not available in the public version of the dataset, but has been recovered from additional data that were made available to me by CentERdata. Appendix B provides more details.

${ }^{20}$ See Appendix E for a detailed description of questions. For online banking usage consumers indicate whether they use online banking 'very rarely', 'every now and then', 'often', or 'very often'.

${ }^{21}$ The exact amount brackets are $€ 0-€ 1,000, € 1,000-€ 2,500, € 2,500-€ 3,500, € 3,500-€ 4,500, € 4,500-$ $€ 7,000, € 7,000-€ 8,000, € 8,000-€ 9,000, € 9,000-€ 10,000, € 10,000-€ 25,000, € 25,000-€ 45,000$, and more than $€ 45,000$. As some of these volume thresholds might fall within these ranges, I manually recover the exact amount thresholds whenever possible.

22 (1) Accounts with minimum amount requirements offer either very low base rates or zero interest rate up to a certain volume threshold and higher rates above that threshold. (2) Accounts with lowest balance bonus give a bonus rate on the lowest account balance within a year or a quarter and yield a base rate on the remaining balance. (3) Accounts with balance growth bonus yield a bonus rate if the balance grows by a specified percentage amount per month or year. (4) Accounts with fixed deposit require a specified absolute deposit each month. (5) Accounts with withdrawal limitations / fees limit the maximum amount that can be withdrawn per month or comprise percentage fees for withdrawals (mostly $1 \%$ of the withdrawn amount). (6) Salary accounts are linked to a checking account at the same bank, which needs to be the income account.
} 
Last, I use bank branch data for all Dutch banks on postcode level from the data provider 'Locatus' covering the entire Netherlands from 2005 to $2008{ }^{23}$ As the most precise information on the location of a consumer in the DHS is the province, I aggregate the branch data to the province level. For each bank, province, and year, I match the total number of branches to the DHS.

I match the other two data sources on account-volume-year-level as follows. As the DHS reports the holdings of financial assets as of December 31 of the year prior to the survey, I match interest rates for the last week of December of each year to the DHS data based on bank name, account name, and invested volume on each individual account ${ }^{24}$ For each savings account held by a member of a household, the matched data ultimately contain the invested volume, account name, bank name, and the applicable interest rate.

\section{B. Sample Composition}

I construct the estimation sample of account users as follows. First, I focus on demand deposits held by adult household members as the data from the comparison website contains only interest rates for variable rate savings accounts, but also to avoid price variation across products simply due to maturity differences ${ }^{25}$ I call this the full sample. It comprises in total 8,775 savings accounts held by 2,130 individuals in the period from 2005 to 2008.

Second, I focus on the main savings account defined as the account with the largest volume share of all accounts held by an individual in a given year comparable to previous studies modeling individual bank choice in a structural framework ${ }^{26}$ This main account covers on average $88.1 \%$ of the total volume held by an individual and still $72.6 \%$ for individuals with more than one account. This approach defines a clear panel variable enabling me to consistently follow each main account over time. As a result, rebalancing across the existing account portfolio of a consumer is counted as a switch arguably entailing little tangible costs but implicit costs such as inattention which my inertia measure is intended to capture as well. 27

\footnotetext{
${ }^{23}$ I am grateful to Thomas Mosk from Goethe University Frankfurt for providing me with this data set.

${ }^{24}$ I recover missing volumes of around $10 \%$ of the individual savings accounts following the procedure used by CentERdata for total savings volumes as described in Appendix B

${ }^{25}$ This would require to incorporate maturity choice into the empirical model later, which is beyond the scope of this paper. However, only around $1.3 \%$ of accounts in the pooled sample are fixed-term deposit accounts making it unlikely that this would affect the results.

${ }^{26}$ See Barone, Felici and Pagnini (2011) and Crawford, Pavanini and Schivardi (2018) using administrative loan data on bank-firm level and Honka, Hortaçsu and Vitorino (2017) using survey data on retail bank choices. This strategy avoids modeling multiple bank relationships per decision maker. In the case of a tie (e.g., $50 \%$ on each of two accounts), I choose the first named account, as this is most likely the most important one for the respondent.

${ }^{27}$ Alternatively, I could treat each individual account as a separate unit of observation as mostly popular in the finance literature, e.g., Ioannidou and Ongena (2010) or Stango and Zinman (2011). This ignores the possibility of rebalancing across accounts entirely and in the current setting makes it problematic to clearly
} 
To construct the final estimation sample, I keep only those cases with matched interest rate, which concerns around $80 \%$ of all accounts held. ${ }^{28}$ To be able to define a switching indicator, only individuals observed at least two consecutive periods enter the sample. Last, I follow a two-step aggregation procedure to reduce the dimension of the choice set. First, for a given bank, I aggregate accounts comprising less than $5 \%$ of the customers of that bank into one account. Second, I aggregate all small banks outside the top 10 '-banks in terms of number of customers into an outside option comprising $2.3 \%$ of the market. The final estimation sample contains in total 40 accounts held by 1,247 individuals resulting in 3,208 observations from 2005 to 2008.

Table A2 in Appendix A compares the three samples across major demographics, market share of banks, and account volume. The descriptives show that all samples are very similar across major socio-demographics. Going from the full to the sample of main accounts, the slight change in market shares suggests that main accounts are not entirely equally distributed across banks 29 Market shares in the final estimation sample show that there are slightly more matched accounts at ING Bank and slightly less at medium and smaller banks. Due to the focus on main accounts, account volume mechanically increases to $€ 15,860$ from $€ 10,700$ in the original sample. Nevertheless, the final estimation sample covers the market quite well in terms of representativeness.

\section{Summary statistics}

Table 1 shows summary statistics for all respondents in the final sample as well as for three separate subgroups of respondents: Non-switchers, switchers within bank, and switchers across bank. I define non-switchers as all respondents who did not switch their main account, while the two groups of switchers either selected a new main account at the same or at a different bank compared to the previous period 30 The average age of all account holders is 52, 57\% are male, $73 \%$ live in a couple household, and the average net income is $€ 22,719$. Moreover, $44 \%$ of the respondents use online banking very often. The table also shows statistics on linked choices potentially affecting the switching decision which are lagged by one year as they should favor the existing default $3159 \%$ of respondents hold only one savings account, $78 \%$ hold all savings accounts at the same bank, $74 \%$ hold, in addition, a salary account, and $19 \%$ a mortgage at their

\footnotetext{
follow accounts over time as the order in which accounts are named by the respondents sometimes change, for example, if accounts are closed.

${ }^{28}$ Unmatched accounts include mainly accounts with missing product name but also reported savings products which were not offered by a specific bank in a particular time period.

${ }^{29}$ For example, ING Bank loses $4 \%$ market share, while Rabobank gains 5\%.

${ }^{30} \mathrm{I}$ do not count switches of products between banks that merged in the previous period as well as passive switches due to name changes of accounts or automatic defaults into newly introduced accounts.

${ }^{31}$ This makes sure that the covariates are predetermined at the time of a savings account choice in year $t$ and correctly relate to the default which is the choice in year $t-1$.
} 
default bank 32 With respect to account characteristics, the three largest banks share around $80 \%$ of the market followed by two medium-sized banks Fortis and SNS Bank and a set of small banks. $40 \%$ of all accounts are internet accounts, while the three most common restrictions are minimum amount (24\%), lowest balance bonus (19\%), and withdrawal limitations (7\%). Some interesting patterns emerge when comparing across groups. Both groups of switchers are significantly more likely to have more than one account in the period before a switch and earn significantly higher interest rates after a switch compared to non-switchers. Consistent with the latter, these groups are also more likely to hold internet accounts. In terms of demographics, the groups are quite homogenous although switchers have slightly higher net income. Comparing within the group of switchers, switchers across banks are significantly more likely to engage in multi-banking but less likely to hold their salary account or mortgages at their main bank prior to a switch. They are also more likely to be customers of smaller banks, use online banking very often, and earn higher interest rates than switchers within banks.

An important feature for my analysis is the existence of substantial cross-sectional and time-series variation in pricing of accounts during the observed time period. Figure 2 plots the distribution of interest rates over time separately for each bank ${ }^{33}$ Compared to the larger incumbent banks, small banks offer the highest rates in most years. Notably, interest rate spreads within a given bank are quite high but vary in size across banks. For example, account rates at ING Bank range from $1 \%$ to $2.9 \%$ in 2006, while rates at Rabobank lie between $2.2 \%$ and $2.8 \%$. In addition, there are significant relative interest rate changes over time both within and across banks. Most notably, the interest rate spread within ING Bank strongly widens and even decreases for some accounts during a time in which the monetary policy rate of the European Central Bank rose from $2 \%$ to $4 \% 34$ In comparison, smaller banks seem to adjust to the ECB rate faster on average despite a few outliers at the bottom of the distribution. Part of this variation in interest rates is driven by banks regularly introducing new accounts and exiting old ones as mentioned in Section [II. For example, ABN Amro introduced three new and discontinued two accounts, while Rabobank offers a stable menu of three accounts over the sample period. These relative price changes both within and across banks are an important element for the empirical framework to estimate price sensitivity and inertia separately from time-invariant unobserved account preferences.

\footnotetext{
${ }^{32}$ I do not directly observe which of the reported checking accounts is the salary account in case of several reported accounts. Here, I select the first reported account as respondents are likely to report their most used account first. As a mortgage is a much higher volume financial instrument, I consider all mortgages on the first and second house.

${ }^{33}$ The rates displayed assume that all account restrictions are fulfilled, i.e., there is sufficient volume on the account to achieve the highest possible rate.

${ }^{34}$ This refers to the interest rate on the main refinancing operations (MRO) of the European Central Bank which provides the bulk of liquidity to the banking system.
} 


\section{Preliminary analysis of inertia}

\section{A. Descriptive evidence}

Documenting inertia in deposit markets is challenging since one would like to distinguish between choice persistence due to frictions as compared to persistent consumer preferences over a rich set of account and bank characteristics. However, I find several descriptive patterns in the data consistent with inertia. Table 2 shows annual switching rates overall and separately for within and across bank switches. Bank switching is between $5.7 \%$ and $7.6 \%$ per year. In addition, only between $5.4 \%$ and $7.4 \%$ of individuals per year switched their main account within their current bank. This is notable given that choice frictions could be expected to be much lower within the same bank as consumers do not incur the costs of switching providers and costs of re-optimization involve a much smaller number of accounts offered. Low switching rates alone, however, do not necessarily suggest inertia but could also indicate low benefits from switching.

In this regard, figure 3 shows the potential benefits from switching over the pooled sample taking into account the differential pricing and availability of accounts for different volumes. From left to right, the upper panel shows the distribution of interest rate benefits from switching to the highest rate account for three cases: within the same bank, across all banks within the same account type, and across all banks and all account types. The first graph shows that, while more than $30 \%$ of consumers select close to the highest rate account within their current bank, the remaining consumers could substantially benefit from switching resulting in an overall mean benefit of $0.89 \%$. Intuitively, when considering switching across all accounts in the same category or all accounts in the market, the benefit distribution shifts more to the right increasing the mean benefit to $1.16 \%$ and $1.75 \%$, respectively. The lower panel addresses the question whether the distribution of interest rate benefits differs over the volume distribution due to the multiplicative nature of switching benefits in deposit markets. It reports the results of a locally weighted regression of interest rate benefits on invested volume for all three cases considered above. The graph shows a clear negative and convex relationship between interest rate benefits and volume. These mean differences are most evident in the first part of the distribution up to $€ 40,000$ and flatten out for higher volumes. This suggests that accounting for varying price sensitivities is an important element in deposit markets.

\section{B. Reduced-form evidence}

Despite the changing choice environment and high potential benefits, there is little movement in consumer choices over time. I now analyze determinants of switching using 
two reduced-form specifications. First, I estimate a pooled linear probability model of account switching on a rich set of controls according to the following specification:

$$
S_{i t}=\lambda \text { Inertia }_{i t}+\xi \text { Benefit } i t+\beta X_{i t}+\gamma_{t}+\epsilon_{i t}
$$

where $S_{i t}$ indicates an account switch from $t$ to $t-1$. Inertia $i t$ is a vector of accountand bank-level switching frictions. First, I include two dummies for single-account and single-bank individuals. 35 Consumers with multiple accounts or banks have likely lower switching costs as they have overcome them in the past. Second, I capture the scope of the bank relationship through separate dummies for the existence of a salary account or mortgage at the default bank. ${ }^{36}$ Holding multiple products at the same bank can generate compatibility benefits, e.g., through access in the same online interface ${ }^{37}$ Last, I include two dummies indicating whether consumers use online banking 'often' or 'very often'. Frequent online banking users are likely to have lower tangible search and switching costs by comparing and opening accounts online ${ }^{38}$ Benefit $t_{i t}$ controls for benefits from switching in two ways. First, I include the relative switching benefit defined as the difference of the default continuation rate from the highest possible rate in the market available to a consumer given his volume. Second, I include account volume (in logs) to control for absolute benefits from switching. $X_{i t}$ includes standard consumer demographics including net income (in logs), age, gender, a couple dummy, a completed high school education dummy, as well as fixed effects for the province and the default bank. Last, $\gamma_{t}$ denotes year fixed effects.

In a second specification, I include, in addition, fixed effects for each individual:

$$
S_{i t}=\lambda \text { Inertia }_{i t}+\xi \text { Benefit }_{i t}+\beta X_{i t}+\gamma_{i}+\gamma_{t}+\epsilon_{i t}
$$

Thus, I exploit the effect of time-varying controls on within-individual variation in the probability of account switching based on the subsample of consumers switching at least once during the sample period 39 As a result, time-invariant demographic controls are not identified and omitted from the model. In both specifications, I cluster standard

${ }^{35}$ Prior studies use comparable proxies. See, e.g., Brown, Guin and Morkoetter 2013) and Brunetti, Ciciretti and Djordjevic (2016) analyzing determinants of switching in deposit markets using micro survey data.

${ }^{30} \mathrm{As}$ before, 1 enter the two former sets of variables lagged by one period to correctly relate them to the default account, i.e., the previous account choice. Unfortunately, my data does not contain information on the bank names of smaller banks for other financial products.

37 Klemperer (1995) cites the need for compatibility between different products as one source of switching costs.

${ }^{38}$ Online banking usage might also correlate with financial sophistication. ? find that the impact of financial literacy on savings account choice can be partially explained by the use of online accounts.

${ }^{39}$ This subsample contains around $30 \%$ of the full estimation sample or 913 observations. 
errors at the individual level to account for intra-group correlation in the error terms. The unconditional probability of switching is $12.9 \%$.

Table 3 reports the correlations for both models. In the first specification, singlebank individuals are 10.7 percentage points less likely to switch, which increases an additional 6.9 percentage points for individuals with only one account. This suggests the existence of both account- and bank-level switching costs. Consumers holding a checking account at their default bank are 6.5 percentage points less likely to switch, while holding a mortgage at the default bank has no additional effect. Thus, the scope of the bank relationship seems to play an important role for savings account choice. In addition, individuals using online banking 'very often' are 5.0 percentage points more likely to switch compared to 'rare' or 'no' online banking users indicating that familiarity with new technology can partially reduce inertia. The results further imply that potential savings are an important albeit quantitatively smaller factor impacting switching. A $1 \%$ higher interest rate benefit increases the probability of switching by 2.7 percentage points, while account volume has no significant effect. Net income has a significant but economically small positive impact on account switching, while the remaining demographics have no effect. In summary, these results suggest potentially several economic explanations of inertia in my setting. One concern is, however, that confounding factors correlated with the included covariates might be omitted from the model resulting in biased parameter estimates.

In the second specification, the inclusion of the individual fixed effects substantially increases the parameter estimates of both the interest rate benefit and account volume compared to the previous specification. A $1 \%$ higher interest rate benefit now increases the switching probability by 18.2 percentage points more than doubling the unconditional probability of switching. A $1 \%$ volume increase now results in a significant 1.6 percentage points increase in the switching probability indicating that within-individual variation in absolute benefits for a given individual can trigger switching. In contrast, all the remaining control variables are now insignificant due to a lack of sufficient within variation over time. This second set of results suggests two things. First, it indicates the importance of accounting for time-invariant unobserved heterogeneity in my setting for the identification of the main parameters of interest. Second, absolute monetary gains from switching can be an important element to explain consumer choice behavior in deposit markets. 


\section{Empirical Framework}

\section{A. Choice Model}

In this section, I build a structural choice model allowing for inertia within and across banks, differential price sensitivities over the volume distribution, and heterogeneous account preferences. Relative to the preceding analysis, this framework allows to quantify inertia and study the impact of counterfactual policies. These additional results should be seen in light of the structural assumptions made in the modeling framework.

In each year $t=1, \ldots, T$, an individual $i=1, \ldots, I$ selects a main savings account $j=1, \ldots, J$ from the set of available accounts at the ten largest banks or decides for the outside option to own a savings account at a small bank. I do not model the participation decision as the overwhelming majority of Dutch consumers owns a savings account. The individual choice set contains all accounts used in a given year available to a consumer given his volume. Thus, for instance, accounts with minimum balance requirements not available to a consumer, do not enter the individual choice set 40 Let individual $i$ 's indirect utility from account $j$ in year $t$ be given by:

$$
\begin{aligned}
U_{i j t} & =a_{i j}\left(\mathbf{X}_{\mathbf{i}}\right)+\alpha\left(\Lambda_{i t}\right) p_{i j t}+\gamma \ln \left(n_{i j t}\right)+\eta^{A}\left(\mathbf{X}_{i t}^{A}\right) y_{i j, t-1}^{A}+\eta^{B}\left(\mathbf{X}_{i t}^{B}\right) y_{i j, t-1}^{B}+\epsilon_{i j t} \\
& =V_{i j t}\left(a_{i j}, p_{i j t}, n_{i j t}, \widehat{\mathbf{y}_{\mathbf{i j}, \mathbf{t}-\mathbf{1}}}, \alpha_{i t}, \gamma, \eta_{i t}\right)+\epsilon_{i j t}
\end{aligned}
$$

where I normalize the constant of the outside option of choosing a savings account at a small bank to zero. Utility depends on a set of individual-specific account intercepts, $a_{i j}\left(\mathbf{X}_{\mathbf{i}}\right)$ as a function of consumers demographics $\mathbf{X}_{\mathbf{i}}$, the interest rate, $p_{i j t}$, the number of branches, $n_{i j t}$, a default indicator, $y_{i j, t-1}$, taking the value one if the savings product in $t$ is the same as in $t-1$. Thus, I model inertia as an implied monetary premium on the default similar in structural interpretation to a tangible switching cost. Note that the interest rate potentially varies over consumers as some accounts have nonlinear pricing structures depending on invested volume. Comparable to previous structural work in deposit markets, I control for benefits from local branch presence through the number of bank branches on province level 41 I use the natural logarithm to capture their declining effect on deposit demand 42

\footnotetext{
${ }^{40}$ Note that in contrast to other work using micro data on loan decisions, e.g. Crawford, Pavanini and Schivardi (2018), I do not have to predict the prices of non-chosen alternatives in a regression framework as interest rates depend only on volume and I can observe the full pricing schedule for each account.

${ }^{41}$ I add further potentially time-varying bank characteristics from the balance sheet database Bankscope in the robustness section including measures for bank size, retail focus, and service quality. These turn out insignificant in my specification mainly due to insufficient variation over time.

${ }^{42}$ Previous studies in deposit markets use comparable transformations. See, e.g., Molnar, Violi and Zhou (2013) and Honka, Hortaçsu and Vitorino 2017).
} 
Some notes on the underlying assumptions of the above specification might be warranted. First, as in most of the previous literature, the model assumes that consumers are myopic and do not make dynamic decisions by, for example, forming expectations about future prices. This assumption seems less severe in the context of retail deposit markets in which interest rate changes depend on a number of factors including the monetary policy of the central bank, conditions in other funding market, and knowledge about the pricing model of banks. As a result, most retail investors should have difficulties to correctly predict future interest rate changes.

Second, the model assumes that consumers have full knowledge of prices and characteristics of all accounts. While this type of information is available on regular comparison websites, consumers might not consult such services for different reasons and instead engage in costly search. Similar to, e.g., Handel (2013) and Polyakova (2016) the inertia parameters I estimate can, thus, be interpreted as the implicit foregone gains from a collection of different frictions. Note that the included account fixed effects control for unobserved time-invariant differences of accounts, e.g., in popularity or marketing, partially mitigating the lack of data on individual consideration sets as in Honka, Hortaçsu and Vitorino (2017).

Finally, I assume that volume is exogenous to the consumer's product choice. Thus, I assume the consumer first solves a portfolio allocation problem in the background determining the share of wealth invested in different asset classes given his risk preferences and then optimizes in each of the asset classes separately. This assumption bridges standard portfolio allocation theory which typically assumes a fixed return of a safe asset which stands in contrast to the wide dispersion of interest rates observed in the data. Equivalently the portfolio allocation problem is solved based on an expected return available in the market for savings accounts, while the degree of optimization in this market does not feed back into a change in the allocation of funds.

\section{B. Identification}

The primary identification concern is to separately identify inertia from unobserved persistent preferences. In this regard, three important issues have to be considered: variation in the choice set over time, separation of spurious vs. structural state dependence, and the initial conditions problem.

As shown in Section III, there is substantial variation in the relative attractiveness of accounts over time both within and across banks through differential pass-through of monetary policy rates as well as variation in the available product set. Variation in account volume further shifts the relative attractiveness of accounts by increasing the benefits from switching or making more attractive accounts with minimum balance requirements available to the consumer. This variation is important as otherwise con- 
sumers might just remain with a once made optimal product choice with the result that the researcher would not observe any switching in the data in the most extreme case ${ }^{43}$

A further challenge is to distinguish spurious from structural state dependence, a pertinent issue in dynamic panel models when a lagged dependent variable is included. Spurious state dependence arises if unobserved individual heterogeneity is correlated over time, while structural state dependence measures the direct impact of last period's choice on today's preferences of a consumer. In general, both of these effects will be captured by the lagged dependent variable when not properly accounted for. Moreover, in the data I cannot observe individual choices from the start of the choice process, i.e., the first time they select a savings account giving rise to the initial conditions problem. This is problematic if the initial condition is correlated with persistent unobserved heterogeneity, see Heckman (1981) ${ }^{44}$ To account for this, I adjust the approach by Wooldridge (2005) to the mixed logit model used in this study. He suggests to model the distribution of the unobserved effect conditional on the initial value and any exogenous explanatory variables. By modeling the choice process conditional on the initial value, the specification indirectly controls for all unobserved persistent heterogeneity correlated with the initial condition. With a properly specified distribution this results in a random coefficient model where the initial choices are included as additional covariates 45 Precisely, the following decomposition of the individual-account effects applies:

$$
a_{i j}=\mu_{j}\left(\mathbf{X}_{\mathbf{i}}\right)+\gamma^{A} y_{i j, 0}^{A}+\gamma^{B} y_{i j, 0}^{B}+\overline{X_{i j}}+\nu_{i j}
$$

where $\nu_{i j} \mid y_{i j, 0}^{A}, y_{i j, 0}^{B} \sim N\left(0, \sigma_{\nu_{j}}^{2}\right)$ and $y_{i j, 0}^{A}$ and $y_{i j, 0}^{B}$ denote the first observed product and bank choice within the considered time period, $\mu_{j}$ is the account-specific intercept, and $\overline{X_{i j}}$ denotes the individual time averages over all time-varying covariates ${ }^{46}$ As the initial conditions are time-invariant, they are identified only from cross-sectional variation in the first observed account and bank choice across consumers. Consequently, the inertia cost parameters are only identified from individuals switching at least once during the observed time period as for those individuals remaining with their default

\footnotetext{
43 Dubé, Hitsch and Rossi (2010) were first to note the importance of time-varying product characteristics for the identification of state dependence.

${ }^{44}$ One immediate example that comes to mind would be anecdotal evidence that most consumers open their first account at the bank of their parents which likely depends on individual preferences of the household.

${ }^{45}$ See Appendix D on initial conditions for further details.

${ }^{46}$ Note that in contrast to Wooldridge (2005), I do not include the individual time averages of the only two time-varying covariates in my model, interest rate and the number of branches. The reason is that the number of branches does not exhibit sufficient variation over time within province and bank, while interest rates are mainly identified from variation over time through the inclusion of the account fixed effects and do not sufficiently vary within a given account across individuals. Thus, comparable to Raymond et al. (2010), the time-constant averages are not separately identified from the already included covariates.
} 
option over the whole panel, the default indicators and the initial conditions coincide. Note that the approach by Wooldridge (2005) actually requires a balanced panel, while the data at stake is of unbalanced nature. This should, however, not introduce any bias if panel attrition is random and is common in the applied literature ${ }^{47}$ Nevertheless, in Section VII. I show that the results are robust using a balanced panel of consumers.

Last, there might be omitted time-varying characteristics incorrectly attributed to inertia. Similar to, e.g., Handel (2013), Polyakova (2016), or Heiss et al. (2016), I make use of the fact that some individuals are forced to make an active choice at each point in time either because they enter the market anew or because their previous account or bank was discontinued without automatic default into a new product. If these two groups of choosers are otherwise similar, then the behavior of the forced choosers alone identifies preferences, while the remaining difference to the optional choosers is attributed to inertia. Table A3 in Appendix A shows that the two groups are quite similar across major sociodemographics although forced choosers more often have a college degree ( $42 \%$ vs. $22 \%$ ) and are more likely to use online banking very often $(44 \%$ vs. $36 \%$ ). Given that both characteristics overlap and inertia is modeled conditional on online banking usage, this should, however, not significantly affect the identification strategy.

In addition, endogeneity of interest rates is a potential concern. First, while typically less severe in micro data, aggregate endogeneity might arise from the simultaneous determination of prices and consumer demand in equilibrium. Second, endogeneity in prices may be present due to omitted account or bank characteristics correlated with interest rates. The account fixed effects included in the model mitigate this problem as long as the perceived differences in accounts and banks are constant over time ${ }^{48}$ While the observed account restrictions rarely change over the sample period, timevarying characteristics, e.g., banks investing differentially in customer service, might still be correlated with interest rates. As standard instrumental variable estimators do not exist for non-linear multinomial models, I use a control function approach as in Petrin and Train (2010). Similar to a first stage regression in an instrumental variables approach, I model the interest rate as a function of account fixed effects, the number of branches, and a set of cost shifters exogenous to the demand equation:

$$
p_{i j t}=a_{j}+\lambda \ln \left(n_{i j t}\right)+\mathbf{W}_{j t} \beta+\kappa_{i j t}
$$

where $\mathbf{W}_{j t}$ denotes the lagged EONIA rate interacted with account fixed effects.

${ }^{47}$ Cf., e.g., Raymond et al. (2010) or Ham, Iorio and Sovinsky (2013).

${ }^{48}$ Note that the account fixed effects also subsume any time-invariant unobserved bank characteristics. 
The EONIA rate is the 1-day average interest rate for all overnight unsecured lending transactions on the EURO zone interbank market which constitutes one of the main alternative funding sources for banks compared to instant-access deposits and, thus, acts as a cost shifter for the opportunity costs of funds 49 I exploit the fact that the EONIA rate is strongly correlated but differentially passed through to different account rates, for instance, due to different funding structures of banks. I include the EONIA rate lagged by one year to allow for delayed pass-through of changes in funding conditions on the interbank market to deposit markets.50 The EONIA rate is unlikely correlated with unobservables in the consumer choice decision under regular market conditions 51 The estimated residuals, $\hat{\kappa}$, from the above pricing regression are then included as an additional covariate in the main specification controlling for unobserved account characteristics varying over time and correlated with interest rates.

\section{Estimation}

The intercepts, $a_{i j}\left(\mathbf{X}_{\mathbf{i}}\right)$, capture persistent preference heterogeneity varying over alternatives and consumers but not over time. For each account, I model heterogeneity over individuals by allowing the random coefficients $a_{i j}\left(\mathbf{X}_{\mathbf{i}}\right)$ to be independently normally distributed with a mean related to observed time-invariant and exogenous consumer demographics, $\mathbf{X}_{\mathbf{i}}$ :

$$
\begin{aligned}
a_{i j} & \rightarrow N\left(\mu_{j}\left(\mathbf{X}_{\mathbf{i}}\right), \sigma_{j}^{2}\right) \\
\mu_{j}\left(\mathbf{X}_{\mathbf{i}}\right) & =\mu_{j}+\beta_{j}\left(\mathbf{X}_{\mathbf{i}}\right)
\end{aligned}
$$

where $\mu_{j}$ is an account intercept capturing unobserved persistent differences across accounts. Unfortunately, due to the size of my estimation sample and the lack of continuous characteristics to describe the large number of accounts, I am not able to include mean variations with respect to demographics for all accounts. I deal with this limitation by including in $\beta_{j}\left(\mathbf{X}_{\mathbf{i}}\right)$ interactions between demographic coefficients and the four previously described account types. In the primary specification, $\mathbf{X}_{\mathbf{i}}$ includes gender, age, and a dummy for couples ${ }^{52} \sigma_{j}^{2}$ is the estimated variance of $a_{i j}$. In addition,

\footnotetext{
${ }^{49}$ The interest rate is calculated by the European Central Bank and reported up to three decimal places. The panel of reporting banks is the same as for the Euribor.

${ }^{50} \mathrm{~A}$ large literature in macroeconomics documents incomplete and delayed pass-through of monetary rates to both deposit and credit markets. See, e.g., De Bondt (2005).

${ }^{51}$ This is similar in vein to the instrumental variable strategy used in Egan, Hortaçsu and Matvos (2017) in deposit markets, or previously in the coffee market, e.g., Draganska, Klapper and Villas-Boas (2010) or Bonnet et al. (2013). The exogeneity assumption might fail in times of financial crisis. However, my sample ends at the end of 2007 before the crisis hit the Netherlands.

${ }^{52}$ I include the mode of age and the couples dummy as they vary minimally over the sample period. One could potentially perform additional robustness checks with more demographic information, although each additional
} 
I allow the price coefficient to be nonlinearly related to invested volume:

$$
\alpha\left(\Lambda_{i t}\right)=\alpha \ln \left(\Lambda_{i t}\right)
$$

The logarithmic transformation ensures a concave relationship between price sensitivity and individual account volume. This is in line with the prior descriptive evidence showing a decreasing convex relationship of interest rate benefits and account volume. Both types of inertia, $\eta\left(\mathbf{X}_{i t}\right)$, are linearly related to consumer demographics and linked choices as follows:

$$
\eta^{\psi}\left(\mathbf{X}_{i t}^{\psi}\right)=\eta_{0}^{\psi}+\eta_{1}^{\psi} \mathbf{X}_{i t}^{\psi}, \quad \text { for } \psi \in\{A, B\}
$$

$\mathbf{X}_{i t}^{A}$ contains potential determinants of account-level inertia, including net income in thousand euros, a dummy indicating whether the depositor held only one savings account in the previous year, and two indicator variables for consumers using online banking 'often' or 'very often'.

$\mathbf{X}_{i t}^{B}$ contains potential determinants of bank-level inertia, including a dummy indicating whether the consumer held all savings accounts at a single bank in the previous year, and two lagged dummies for the existence of a salary account or mortgage at the default bank.

Finally, I assume that the individual-account-time specific error term $\epsilon_{i j t}$ is i.i.d. type 1 extreme value distributed following the literature on demand estimation in differentiated product markets. I estimate the choice model using simulated maximum likelihood techniques as described in Train (2009). As I use panel data, I model the probability of observing a sequence of choices for each depositor. Since the estimation algorithm is similar to a standard approach, I describe the remainder of the details in Appendix C.

\section{Results}

\section{A. Parameter Estimates}

Figure 4 compares predicted and actual market shares on account level for the pooled sample to evaluate the fit of the primary choice model specification. ${ }^{53}$ It shows that the

demographic variable increases the parameters to be estimated by the number of account types. I chose not to include interactions between demographics and bank-specific indicators as those turned out to be insignificant in a number of reduced form regressions.

${ }^{53}$ Predicted market shares are calculated in an iterative process from one year to the next as the probability of choosing a specific account as predicted by the model in a given year forms the now itself random default account probability in the next year. 
model is able to fit the observed patterns in the data fairly well as the predictions for accounts both with small and large market share are very much in line with the actual market shares. This suggests that the distributional and functional form assumptions imposed by the model are not too restrictive.

Table 4 shows the estimates of the primary choice model. Model 1 reports the results of a simple conditional logit model including lagged indicators for previous bank and account choice, the log number of branches, account preferences, and the control function. Model 2 adds initial conditions for the first bank and account choice observed for each individual. 54 The last model shows estimates from a full mixed logit model with random parameters. All results show utility parameters measured in utils not marginal effects and are, thus, only interpretable in relative size to each other. Adding the initial values reduces, as expected, the estimated parameters of the lagged indicators for previous bank and account choice suggesting that accounting for spurious state dependence correlated with the initial condition is important in my setting. The parameter estimates further decrease when allowing for more unobserved heterogeneity in the full model. The interaction of interest rate and log account volume is highly significant and enters with the expected positive sign. Both inertia parameters are significant at 1\%-level and substantially impact utility. The reported population means show that switching accounts across banks is around one third costlier compared to switching within banks. The common inertia cost component increases by around one fourth for individuals with only one account but decreases by around one sixth for frequent online banking users compared to the base category. While the base parameter of the default bank is insignificant, single-bank consumers and consumers with a checking account have significantly larger inertia across banks. In contrast, holding a mortgage at the default bank does not significantly impact inertia. This suggests that switching costs and the scope of the bank relationship mainly explain the inertia cost premium for switching across banks.55 The substantial inertia within banks suggests that unmeasured behavioral explanations beyond tangible search and switching costs likely play a role. Recent survey evidence from 2014 conducted by the marketing research institute GFK on a representative sample of Dutch consumers on behalf of the Dutch competition authority supports this suspicion 56 Among those respondents that did not switch in the last 12 months, more than half are not aware of the interest rate on their account, $70 \%$ are either unfamiliar with the Dutch deposit guarantee scheme or give a wrong description of it, and more than $50 \%$ do not expect to receive a higher interest rate at a different bank.

\footnotetext{
${ }^{54}$ Data from 2004 provide the initial conditions for 2005.

${ }^{55}$ Note that the model also estimates mean and standard deviation for each of the 40 accounts which are not shown due to the large number of parameters but are available from the author upon request.

${ }^{56}$ See ACM (2014).
} 
Comparable to previous work, I find that the number of branches has a significant and large positive impact on savings account choice confirming the importance of local bank presence. With respect to account preferences, the results show that the included demographics capture some meaningful heterogeneity across consumers. Male consumers are significantly less likely to demand restricted accounts and both types of internet accounts as compared to the base outcome of unrestricted plain accounts. Intuitively, older consumers are significantly less likely to demand internet accounts, while living in a couple household does not impact account preferences. Last, the significant control function shows the importance of accounting for omitted time-varying account characteristics correlated with interest rates in my setting.

To translate the inertia coefficients from utils into monetary willingness-to-pay, I first divide the utility weight of inertia, $\eta^{A}$ and $\eta^{B}$ by the respective individual interest rate coefficients, $\alpha\left(\Lambda_{i t}\right)$, measuring the marginal utility of money relative to invested volume. The individual price sensitivity and inertia parameters imply a full inertia distribution according to:

$$
\frac{\eta_{i t}^{\psi}}{\alpha\left(\Lambda_{i t}\right)}=\frac{\eta_{i t}^{\psi}}{\alpha \ln \left(\Lambda_{i t}\right)}, \quad \text { for } \psi \in\{A, B\}
$$

In addition, I calculate absolute monetary inertia costs by multiplying the expression above with the invested volume on each individual account. Figure 5 shows the implied inertia distribution within and across banks in percent of volume (upper panel), in absolute terms (middle panel), and in relation to volume (lower panel) ${ }^{57}$ I report key points of the distribution in the table below. The estimates reveal large and heterogeneous inertia. The median relative inertia costs within banks are $2.7 \%$ or $€ 180$ with a standard deviation of $2.3 \%$ (€560), while inertia costs across banks are on average $3.5 \%$ or $€ 460$ with a standard deviation of $3.0 \%(€ 720) 58$ A noteworthy feature is the highly right-skewed distribution of absolute inertia costs as shown in the middle panel, mainly driven by the skewed distribution of volume. As a result, the median inertia costs lies around $50 \%$ below the mean estimate. The lower panel shows, in addition, the relationship of inertia with volume both in relative and absolute terms. While relative inertia costs are substantial for lower volumes, they sharply fall for higher volumes ranging from $6.5 \%$ at the $5 \%$-percentile to $2.8 \%$ at the $95 \%$-percentile. These findings resonate with a large household finance literature emphasizing the role of wealth for op-

\footnotetext{
${ }^{57}$ The upper panel excludes account volumes below the 5\%-percentile or $€ 112$. The two lower panels exclude, in addition, account volumes above the $99 \%$-percentile or $€ 126000$ for better visual inspection.

${ }^{58}$ While these estimates seem substantial, they are in line with the few earlier studies quantifying inertia based on aggregate data. Shy (2002) estimates switching costs in the range from $0 \%$ to $11 \%$ for the Finnish deposit market using aggregate data on prices and market shares, while Kim, Kliger and Vale (2003) estimate average switching costs of $4.1 \%$ in the Norwegian loan market.
} 
timizing behavior of households in the presence of fixed costs, as reviewed in Campbell (2006) or Guiso, Sodini et al. (2013). For example, Vissing-Jorgensen (2003) notes that if irrational behavior is weaker for investors with higher wealth or income, this points to information or transaction costs as a potentially important contributing factor for these behaviors.

In contrast, absolute inertia almost linearly increases with volume ranging from $€ 10$ at the $5 \%$-percentile to $€ 1740$ at the $95 \%$-percentile. This might indicate higher opportunity costs of time for wealthier depositors or a diminishing marginal utility of money. Taken together, the findings suggest that limited monetary switching benefits of a large group of less affluent consumers are an important determinant of low switching rates in the presence of large interest rate differentials in this market. This stands in stark contrast to prior work in the Industrial Organization literature disregarding the role of wealth for financial decision making in the presence of frictions when prices are multiplicative.

\section{B. Robustness}

Table 5 reports three robustness checks to examine the sensitivity of the results to the modeling assumptions. Model 1 shows results using a balanced panel of consumers as the method by Wooldridge (2005) used in this paper, ideally relies on balanced panel data. Unfortunately, this significantly reduces the sample to 431 individuals each observed over four years. While the estimation loses some efficiency due to the smaller sample size, the results are quite comparable to the main model specification. For example, the coefficient for the interaction of interest rate and log account volume is 0.172 compared to 0.137 previously and the coefficient for the default account changes from an earlier 3.24 to 3.07 now.

Model 2 excludes accounts with volume above $€ 40,000$ not covered by deposit insurance during the observed time period 59 For those consumers perceived differences in banks' riskiness might be wrongly attributed to inertia. Both the price coefficients as well as the inertia parameters are highly comparable suggesting that this does not significantly impact the estimates.

Model 3 further addresses the concern that important time-varying bank characteristics might be omitted from the model. Due to the lack of regulatory data, I retrieve additional balance sheet information from Bankscope, a widely used database in the empirical banking literature. For comparability, I focus on items reported according to IFRS accounting standards. I then add several additional control variables to my main specification. First, I include total assets in billion euros to control for bank size

${ }^{59}$ As most volumes lie below that threshold, this concerns only $8.8 \%$ of the sample. 
as in Dick (2007, 2008). I also add the core deposit ratio defined as the ratio of overall customer deposits over total assets to control for the retail focus of a bank. Moreover, I use the ratio of personel expenses over total operating expenses as a measure for service quality. Last, I add the total number of provinces a bank is active in based on the branch data as in Molnar, Violi and Zhou (2013) 60 The results show that none of the additionally included covariates significantly impact consumer choices, mainly due to little time series variation in these covariates during my sample period.

\section{Implications for Bank Pricing}

The previous description of a market with differentiated products and consumer inertia coupled with imperfect competition creates two opposing effects from the perspective of optimal dynamic pricing of banks. As banks can rationally expect that new customers become locked-in in the future, they face a trade-off between 'harvesting' and 'investing'. Harvesting describes the incentive of setting lower interest rates to exploit the existing customer base, while investing describes the incentive of pricing more aggressively to gain new customers. If firms cannot discriminate between new and old consumers as in the current setting, both effects work against each other. As described in Farrell and Klemperer (2007), the former effect will likely dominate for larger banks as the higher profit per existing customer (intensive margin) outweighs the profit from extending the customer base (extensive margin). This logic reverses for smaller competitors wanting to gain market share. With differentiated products and multi-product firms, predicting the equilibrium in the resulting dynamic pricing game is difficult and can only be solved numerically as in Dubé, Hitsch and Rossi (2009). While certainly worthwhile to explore, I instead provide evidence consistent with the results from the theoretical literature.

While banks cannot directly price discriminate between existing and incoming customers, they can segment their pricing schedules depending on the share of existing customers in different accounts 61 As described in Klemperer (1995), new products will first be marketed to a higher share of incoming customers. As the product matures over time, the share of locked-in customers gradually increases giving firms more pricing power for older products. This implies that older accounts should pay lower rates conditional on account differentiation. To test this hypothesis, I aggregate my dataset to the account-year level 62 In comparison to the prior analysis, I do not aggregate

\footnotetext{
${ }^{60}$ I average all balance sheet items in the category 'Small banks' weighted by total assets, while I take the raw mean for the total number of regions.

${ }^{61}$ Note that in very few cases banks offer teaser rates for a maximum of six months according to information by the comparison website Spaarinformatie which are, however, not contained in the data set. While this presents a form of price discrimination, the practice is not widespread in the Netherlands and its overall impact on prices is small compared to the pricing strategy described below.

62 Anderson, Ashton and Hudson (2014) and Barone, Felici and Pagnini 2011) similarly test pricing implica-
} 
accounts with small market share to adequately define account age and increase the sample size to improve efficiency in the estimation. As my data does not contain information on the exact account age, I proxy this variable by counting the number of years an account has appeared in the DNB household survey since the year 2001.63 I then run three separate regressions of the account rate for the volumes $€ 1000$, $€ 10000$, and $€ 50,000$ on a number of controls using the following specification:

$$
p_{j t}=c_{0}+l_{j t}+\mathbf{r}_{\mathbf{j}} \beta+\gamma t_{t}+u_{j t}
$$

where $l_{j t}$ denotes account age since the year $2001, \mathbf{r}_{\mathbf{j}}$ contains all available account restriction indicators including a dummy for internet accounts and bank fixed effects, and $t_{t}$ are year fixed effects. Table 6 shows that while accounts up to three years old do not pay significantly lower rates than recently introduced accounts, older accounts pay significantly less with increasing account age for all volumes considered. For example, five years old accounts pay on average $0.64 \%$ and seven years old accounts $1.1 \%$ less than recently introduced accounts for a volume of $€ 10,000$. This suggests that banks might indeed incorporate inertia in their pricing ${ }^{64}$ In addition, conditional on account restrictions and account age, customers of ING Bank as one of the largest banks receive on average $0.72 \%$ to $0.95 \%$ less than customers at smaller banks over all volumes considered, while the two medium banks Fortis and SNS Bank, are on average between $0.28 \%$ and $0.69 \%$ below the rates set by smaller banks. The only exception is Rabobank offering no significantly different rates compared to the smaller banks. This is consistent with the theoretical predictions that larger incumbents should have stronger incentives to exploit their relatively large customer base compared to smaller banks aiming to gain market share.

\section{Counterfactual Simulations}

In this section, I evaluate the impact of two counterfactual policies given the model estimates of the primary specification in Section VI in a partial equilibrium framework holding prices fixed. Thus, counterfactual enrollment patterns do not feed back into strategic rate adjustments by banks and should be interpreted with caution regarding long-run predictions. In both counterfactuals, I consider the impact of a policy improving individual choices by reducing inertia. The counterfactual analysis broadly applies to any policies with the potential to reduce inertia: targeted information provision,

\footnotetext{
tions of switching costs in deposit and loan markets.

${ }^{63}$ This is the first year of data in which account names are observed in the DHS.

64 Anderson, Ashton and Hudson (2014) find qualitatively similar results by comparing prices of accounts less and more than 30 months old in a regression framework.
} 
prominent placement of interest rates online, rate change alerts, standardized product information sheets, or the simplification of product portfolios are often cited examples by regulatory institutions 65 While I shed some light on the underlying sources of inertia in Section VI, I evaluate a reduction of the structural inertia parameters from the primary specification, as a large part of inertia within bank remains unexplained. Formally, I evaluate a reduction of inertia by a multiplicative factor $Z$ so that the counterfactual inertia becomes $Z\left(\eta_{A}, \eta_{B}\right)$. The indirect utility then becomes:

$$
U_{i j t}=V_{i j t}\left(a_{i j}, p_{i j t}, n_{i j t}, \widehat{\mathbf{y}_{\mathbf{i j}, \mathbf{t}-\mathbf{1}}}, \alpha_{i t}, \gamma, Z \eta_{i t}\right)+\epsilon_{i j t}
$$

In all simulations, I take the initial condition of each consumer as predetermined in line with the primary choice specification which is modeled conditional on the initial condition. Given the deterministic initial condition, consumers choose the account that maximizes their utility in year $t$ subject to the estimates from the primary specification and counterfactual inertia. As the model cannot predict with certainty which account or bank will be chosen, the simulated choice probabilities of the previous year, $\widehat{\mathbf{y}_{\mathbf{i j}, \mathbf{t}-\mathbf{1}}}$, replace the default account and bank in the current year. This iterative process is repeated until the last observed period.

I then evaluate how much consumers could gain through improved choices under the counterfactual scenarios. In this process, I treat inertia costs as a real social cost and assume the policy to reduce inertia is costless. Thus, reductions in inertia have a direct positive surplus impact for consumers. Due to consumer-level heterogeneity in the choice model, the resulting consumer surplus has to be again approximated by simulation. Following Small and Rosen (1981), I use the compensating variation to evaluate the change in consumer surplus:66

$$
C V_{i t}=\frac{1}{\alpha\left(\Lambda_{i t}\right)}\left|\int\left[\ln \sum_{j=1}^{J} e^{V_{i j t}^{p o s t}}-\ln \sum_{j=1}^{J} e^{V_{i j t}^{p r e}}\right] d \Phi\left(\mathbf{a} \mid \theta^{p r e}\right)\right|
$$

where the superscript 'pre' defines the original scenario before the change, 'post'

\footnotetext{
${ }^{65}$ The Dutch financial markets authority recently imposed a number of requirements on Dutch banks in its Modern Savings Policy Directive. Among other measures, the program limits the number of accounts offered, requires justification of interest rate differences across account types, and imposes significant disclosure requirements on banks towards their customers (PWC $(2015))$.

${ }^{66}$ Note that the formula used assumes that the marginal utility of income is constant. However, this restriction is actually less severe in practice as described in Train (2009), as it only needs to be constant over the range of implicit income changes that are considered by the policy. Thus, the formula still holds for small income changes relative to a person's overall income, which is likely to hold in the current setting.
} 
the alternative scenario after the policy change, and the vector $a$ contains all random parameters. The coefficient $\alpha\left(\Lambda_{i t}\right)$ describes as before the price coefficient of individual $i$ in time $t$ and translates the utility changes into monetary units. The integral is again approximated by simulation using 200 Halton draws.

In the first counterfactual, I proportionally reduce both inertia parameters by four different values of $Z=[0.75,0.50,0.25,0.00]$. Figure 6 presents the evolution of counterfactual market shares for the five largest banks and the set of small banks. As inertia decreases, especially ING Bank loses significant market share, while smaller banks with on average higher interest rates gain market share. In the most extreme case, in which inertia is fully eliminated, ING Bank and the set of smaller banks converge to the same market share at the end of the sample period. In contrast, the remaining large and medium banks remain almost unaffected in all scenarios suggesting that non-price characteristics are valued enough by consumers to prevent bank switching in the presence of lower inertia.

In the second counterfactual, I eliminate inertia costs within banks (i.e., $\eta_{\text {post }}^{A}=0$ ) but leave costs for switching across banks at the baseline level (i.e., $\eta_{\text {post }}^{B}=\eta_{\text {pre }}^{A}+\eta_{\text {pre }}^{B}$ ). This gives an insight into the question how much consumers could gain by optimizing at no cost within their existing bank. It also shows the importance of modeling withinprovider switching which has not been done in previous work, presumably due to data limitations 67

Table 7 presents the changes in consumer surplus per year in absolute terms and in percent of volume for both counterfactuals for the population average, population median, volume quartiles, and major demographics. I start by discussing the results of a $50 \%$ reduction in inertia in column 2 . The average surplus gain is $€ 177$ while the median gain of $€ 85$ is substantially lower consistent with the skewed distribution of volume. There is, in particular, lots of heterogeneity depending on invested volume. The average gain in consumer surplus in the lowest volume quartile is only $€ 10$ per year but substantially increases to $€ 483$ in the highest quartile. In terms of demographics, individuals with a partner and male consumers gain slightly more compared to singles and female consumers which to a large extent can be explained by higher average volumes in these two groups. Quite noticeable, the change in consumer surplus for individuals above 65 is almost four times higher than for younger consumers below 30. This is despite the fact that younger consumers gain more in relative terms and can, thus, again mainly be attributed to higher account holdings of seniors. Intuitively, the results become stronger with increasing policy effectiveness, i.e., a higher reduction

\footnotetext{
${ }^{67}$ Only few papers have the product chosen within provider available. A simplifying assumption made is often that consumers choose the most popular contract offered by a specific provider. Examples include Honka, Hortaçsu and Vitorino (2017) and Hortaçsu, Madanizadeh and Puller (2017).
} 
of inertia. The last column shows the results of the second counterfactual simulation. When optimizing at no cost within banks, consumer surplus increases by $€ 98$ each year on average ranging from $€ 5$ to $€ 268$ from the lowest to the highest volume quartile. In comparison with the first counterfactual, this amounts to around one third of the surplus gains from an overall elimination of inertia. This shows that modeling provider switching alone might neglect an important aspect of inertia. Due to the partial equilibrium framework, the exact magnitudes of these results should, however, be treated with caution.

\section{Conclusion}

In this paper, I develop a structural choice model to disentangle inertia within and across banks in the Dutch retail deposit market. The use of detailed consumer-level panel data allows me to account for both observed and unobserved preference heterogeneity which could alternatively generate the observed choice persistence. I find substantial and heterogeneous inertia which is around one third higher for switching accounts across compared to switching within banks. Observable proxies of bank-level switching costs determine most of this cost premium, while online banking usage reduces inertia. The implied inertia costs decrease in relative terms but increase in absolute monetary terms with invested volume. Thus, limited monetary switching benefits of a large group of less affluent depositors can partially explain low switching rates despite substantial interest rate differences in this market.

While these findings are specific to my setting, such as the observed interest rate environment, the substantial inertia within banks suggests that choice frictions beyond tangible search and switching costs incurred on bank level play a role. Regulatory efforts to facilitate bank switching may, thus, be most effective when combined with policies to improve consumer choices: Rate change alerts, prominent placements of interest rates online, standardized product information sheets, or simplification of product assortments are often discussed examples in this direction.

Carefully designed regulatory measures might result in high potential savings for consumers. In a partial equilibrium framework, I find that reducing inertia shifts market share to more competitive smaller banks, but only eliminating inertia within banks already results in significant gains in consumer surplus. On a macro level, the resulting increased price sensitivity of depositors can enhance the monetary transmission channel when banks find it more profitable to pass-through policy rate changes as a result ECB (2009)).

Improved consumer choices will also have supply side implications not considered in this work. I find evidence that banks incorporate inertia in their pricing as older accounts with a likely higher share of inert customers pay lower rates than comparable 
newer accounts. This kind of dynamic pricing could, in theory, either increase or decrease interest rates compared to the competitive benchmark depending on whether the incentive for a bank to invest in customer acquisition outweighs the incentive to exploit its existing customer base. 68 Even in the latter case, an overall welfare assessment of inertia in the banking sector remains ambiguous due to the potential trade-off between competition and systemic stability. Positive effects of inertia on funding stability of banks could, in principle, outweigh any harmful effects on competition 69 This paper mainly focuses on the demand side but these are intriguing questions for future research.

\section{References}

ACM. 2014. "Barriers to entry into the Dutch retail banking sector."

Andersen, Steffen, John Y Campbell, Kasper Meisner Nielsen, and Tarun Ramadorai. 2018. "Inattention and inertia in household finance: Evidence from the Danish mortgage market." National Bureau of Economic Research.

Anderson, Robert DJ, John K Ashton, and Robert S Hudson. 2014. "The influence of product age on pricing decisions: An examination of bank deposit interest rate setting." Journal of International Financial Markets, Institutions and Money, 31: 216-230.

Barone, Guglielmo, Roberto Felici, and Marcello Pagnini. 2011. "Switching costs in local credit markets." International Journal of Industrial Organization, 29(6): 694-704.

Bilias, Yannis, Dimitris Georgarakos, and Michael Haliassos. 2010. "Portfolio inertia and stock market fluctuations." Journal of Money, Credit and Banking, 42(4): 715-742.

Bonnet, Celine, Pierre Dubois, Sofia B Villas Boas, and Daniel Klapper. 2013. "Empirical evidence on the role of nonlinear wholesale pricing and vertical restraints on cost pass-through." Review of Economics and Statistics, 95(2): 500-515.

Brown, Martin, Benjamin Guin, and Stefan Morkoetter. 2013. "Switching costs, deposit insurance, and deposit withdrawals from distressed banks." Swiss Institute of Banking and Finance Working Paper 19.

Brunetti, Marianna, Rocco Ciciretti, and Ljubica Djordjevic. 2016. "The determinants of household's bank switching." Journal of Financial Stability, 26: 175-189.

Brunnermeier, Markus K, and Stefan Nagel. 2008. "Do wealth fluctuations generate time-varying risk aversion? Micro-evidence on individuals." American Economic Review, 98(3): 713-36.

Campbell, John Y. 2006. "Household finance." The journal of finance, 61(4): 1553-1604.

Carbo-Valverde, Santiago, Timothy H Hannan, and Francisco Rodriguez-Fernandez. 2011. "Exploiting old customers and attracting new ones: The case of bank deposit pricing." European Economic Review, 55(7): 903-915.

CMA. 2016. "Retail banking market investigation. Final report."

Crawford, Gregory S, Nicola Pavanini, and Fabiano Schivardi. 2018. "Asymmetric Information and Imperfect Competition in Lending Markets." The American Economic Review (forthcoming).

Crawford, Gregory S, Nicola Tosini, and Keith Waehrer. 2011. "The Impact of'Rollover'Contracts on Switching Costs in the UK Voice Market: Evidence from Disaggregate Customer Billing Data." CEPR Discussion Paper No. 8693.

${ }^{68}$ See, e.g., Dubé, Hitsch and Rossi 20092010 ) analyzing state dependence in consumer brand choices. 69 Vives (2010) summarizes several reasons for the inherent fragility of the banking sector including inefficient bank run equilibria due to a coordination problem of depositors and excessive risk taking incentives of banks due to limited liability. Competition can exacerbate these problems, while the social costs of bank failures are high. 
Cruijsen, Carin, Maaike Diepstraten, et al. 2017. "Banking Products: You Can Take Them with You, So Why Don't You?" Journal of Financial Services Research, 52(1): 123-154.

Dick, Astrid A. 2007. "Market size, service quality, and competition in banking." Journal of Money, Credit and Banking, 39(1): 49-81.

Dick, Astrid A. 2008. "Demand estimation and consumer welfare in the banking industry." Journal of Banking \& Finance, 32(8): 1661-1676.

DNB. 2009. "ZBO-Verantwoording 2008."

DNB. 2015. "Perspective on the structure of the Dutch banking sector."

Draganska, Michaela, Daniel Klapper, and Sofia B Villas-Boas. 2010. "A larger slice or a larger pie? An empirical investigation of bargaining power in the distribution channel." Marketing Science, 29(1): 57-74.

Dubé, Jean-Pierre, Günter J Hitsch, and Peter E Rossi. 2009. "Do switching costs make markets less competitive?" Journal of Marketing Research, 46(4): 435-445.

Dubé, Jean-Pierre, Günter J Hitsch, and Peter E Rossi. 2010. "State dependence and alternative explanations for consumer inertia." The RAND Journal of Economics, 41(3): 417-445.

ECB. 2009. "Monthly bulletin August."

Egan, Mark, Ali Hortaçsu, and Gregor Matvos. 2017. "Deposit competition and financial fragility: Evidence from the us banking sector." The American Economic Review, 107(1): 169-216.

Farrell, Joseph, and Paul Klemperer. 2007. "Coordination and lock-in: Competition with switching costs and network effects." Handbook of Industrial Organization, 3: 1967-2072.

FCA. 2015. "Cash savings market study report."

Gambacorta, Leonardo, Luigi Guiso, Paolo Mistrulli, Andrea Pozzi, and Anton Tsoy. 2017. "The Cost of Distorted Financial Advice-Evidence from the Mortgage Market." Einaudi Institute for Economics and Finance (EIEF).

Goettler, Ronald L, and Karen Clay. 2011. "Tariff choice with consumer learning and switching costs." Journal of Marketing Research, 48(4): 633-652.

Grubb, Michael D, Matthew Osborne, et al. 2015. "Cellular service demand: Biased beliefs, learning, and bill shock." American Economic Review, 105(1): 234-71.

Guiso, Luigi, Paolo Sodini, et al. 2013. "Household Finance: An Emerging Field." Handbook of the Economics of Finance, 2: 1397-1532.

Ham, John C, Daniela Iorio, and Michelle Sovinsky. 2013. "Caught in the bulimic trap? Persistence and state dependence of bulimia among young women." Journal of Human Resources, 48(3): 736-767.

Handel, Benjamin R. 2013. "Adverse selection and inertia in health insurance markets: When nudging hurts." The American Economic Review, 103(7): 2643-2682.

Hannan, Timothy H, and Robert M Adams. 2011. "Consumer switching and firm pricing: Evidence from bank pricing of deposit accounts." The Journal of Industrial Economics, 59(2): 296-320.

Heckman, James J. 1981. "Heterogeneity and state dependence." In Studies in labor markets. 91-140. University of Chicago Press.

Heiss, Florian, Daniel McFadden, Joachim Winter, Amelie Wuppermann, and Bo Zhou. 2016. "Inattention and switching costs as sources of inertia in Medicare Part D." National Bureau of Economic Research.

Ho, Kate, Joseph Hogan, and Fiona Scott Morton. 2017. "The impact of consumer inattention on insurer pricing in the Medicare Part D program." The RAND Journal of Economics (forthcoming).

Honka, Elisabeth. 2014. "Quantifying search and switching costs in the US auto insurance industry." The Rand Journal of Economics, 45(4): 847-884.

Honka, Elisabeth, Ali Hortaçsu, and Maria Ana Vitorino. 2017. "Advertising, consumer awareness, and choice: Evidence from the US banking industry." The RAND Journal of Economics, 48(3): 611-646.

Hortaçsu, Ali, Seyed Ali Madanizadeh, and Steven L Puller. 2017. "Power to Choose? An Analysis 
of Consumer Inertia in the Residential Electricity Market." American Economic Journal: Economic Policy, 9(4): 192-226.

Ioannidou, Vasso, and Steven Ongena. 2010. "Time for a change: Loan conditions and bank behavior when firms switch banks." The Journal of Finance, 65(5): 1847-1877.

Kim, Moshe, Doron Kliger, and Bent Vale. 2003. "Estimating switching costs: The case of banking." Journal of Financial Intermediation, 12(1): 25-56.

Kiser, Elizabeth K. 2002. "Household switching behavior at depository institutions: Evidence from survey data." Antitrust Bulletin, 47: 619.

Kiss, András. 2017. "Salience and switching." Working paper, Amsterdam University.

Klemperer, Paul. 1995. "Competition when consumers have switching costs: An overview with applications to industrial organization, macroeconomics, and international trade." The Review of Economic Studies, 62(4): 515-539.

Luco, Fernando. 2016. "Switching costs and competition in retirement investment." Working paper, Texas A\&M University.

Madrian, Brigitte C, and Dennis F Shea. 2001. "The power of suggestion: Inertia in 401 (k) participation and savings behavior." The Quarterly Journal of Economics, 116(4): 1149-1187.

Molnar, Jozsef, Roberto Violi, and Xiaolan Zhou. 2013. "Multimarket contact in Italian retail banking: Competition and welfare." International Journal of Industrial Organization, 31(5): 368-381.

Pavlidis, Polykarpos, and Paul B Ellickson. 2017. "Implications of Parent Brand Inertia for Multiproduct Pricing." Quantitative Marketing and Economics, 15(4): 304-343.

Petrin, Amil, and Kenneth Train. 2010. "A control function approach to endogeneity in consumer choice models." Journal of Marketing Research, 47(1): 3-13.

Polyakova, Maria. 2016. "Regulation of insurance with adverse selection and switching costs: Evidence from Medicare Part D." American Economic Journal: Applied Economics, 8(3): 165-195.

PWC. 2015. "Cash savings - An international comparison."

Raymond, Wladimir, Pierre Mohnen, Franz Palm, and Sybrand Schim Van Der Loeff. 2010. "Persistence of innovation in Dutch manufacturing: Is it spurious?" The Review of Economics and Statistics, 92(3): 495-504.

Sharpe, Steven A. 1997. "The effect of consumer switching costs on prices: A theory and its application to the bank deposit market." Review of Industrial Organization, 12(1): 79-94.

Shum, Matthew. 2004. "Does advertising overcome brand loyalty? Evidence from the breakfast-cereals market." Journal of Economics \& Management Strategy, 13(2): 241-272.

Shy, Oz. 2002. "A quick-and-easy method for estimating switching costs." International Journal of Industrial Organization, 20(1): 71-87.

Small, Kenneth A, and Harvey S Rosen. 1981. "Applied welfare economics with discrete choice models." Econometrica, 49(1): 105-30.

Stango, Victor, and Jonathan Zinman. 2011. "Fuzzy math, disclosure regulation, and market outcomes: Evidence from truth-in-lending reform." Review of Financial Studies, 24(2): 506-534.

Sudhir, K, and Nathan Yang. 2014. "Exploiting the choice-consumption mismatch: A new approach to disentangle state dependence and heterogeneity." Cowles Foundation Discussion Paper No. 1941.

Teppa, Federica, and Corrie Vis. 2012. "The CentERpanel and the DNB Household Survey: Methodological aspects." DNB Occasional Studies 4, De Nederlandsche Bank.

Thaler, Richard H, and Cass R Sunstein. 2008. Nudge: Improving decisions about health, wealth, and happiness. Yale University Press.

Train, Kenneth E. 2009. Discrete choice methods with simulation. Cambridge University Press.

Vissing-Jorgensen, Annette. 2003. "Perspectives on behavioral finance: Does" irrationality" disappear with wealth? Evidence from expectations and actions." NBER macroeconomics annual, 18: 139-194. 
Vives, Xavier. 2010. "Competition and stability in banking." CESifo Working Paper No. 3050.

Woodward, Susan E, and Robert E Hall. 2012. "Diagnosing consumer confusion and sub-optimal shopping effort: Theory and mortgage-market evidence." American Economic Review, 102(7): 3249-76.

Wooldridge, Jeffrey M. 2005. "Simple solutions to the initial conditions problem in dynamic, nonlinear panel data models with unobserved heterogeneity." Journal of Applied Econometrics, 20(1): 39-54. 

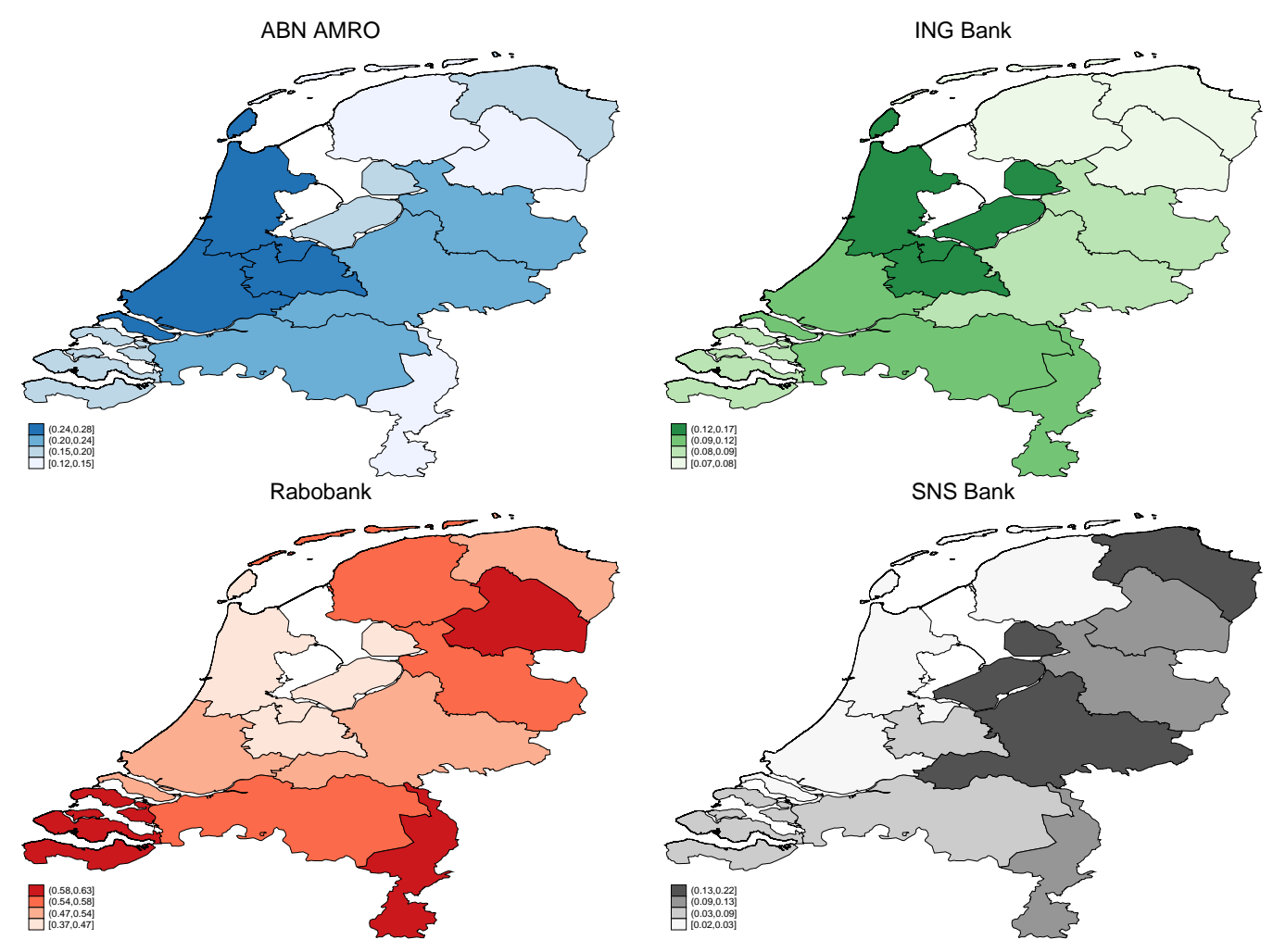

Figure 1. Geographic distribution of BRAnCh Share

Note: The figure shows the spatial distribution of the branch share defined as the number of branches of each bank over the total number of branches in each province across the twelve Dutch provinces for the four largest banks in 2005. 

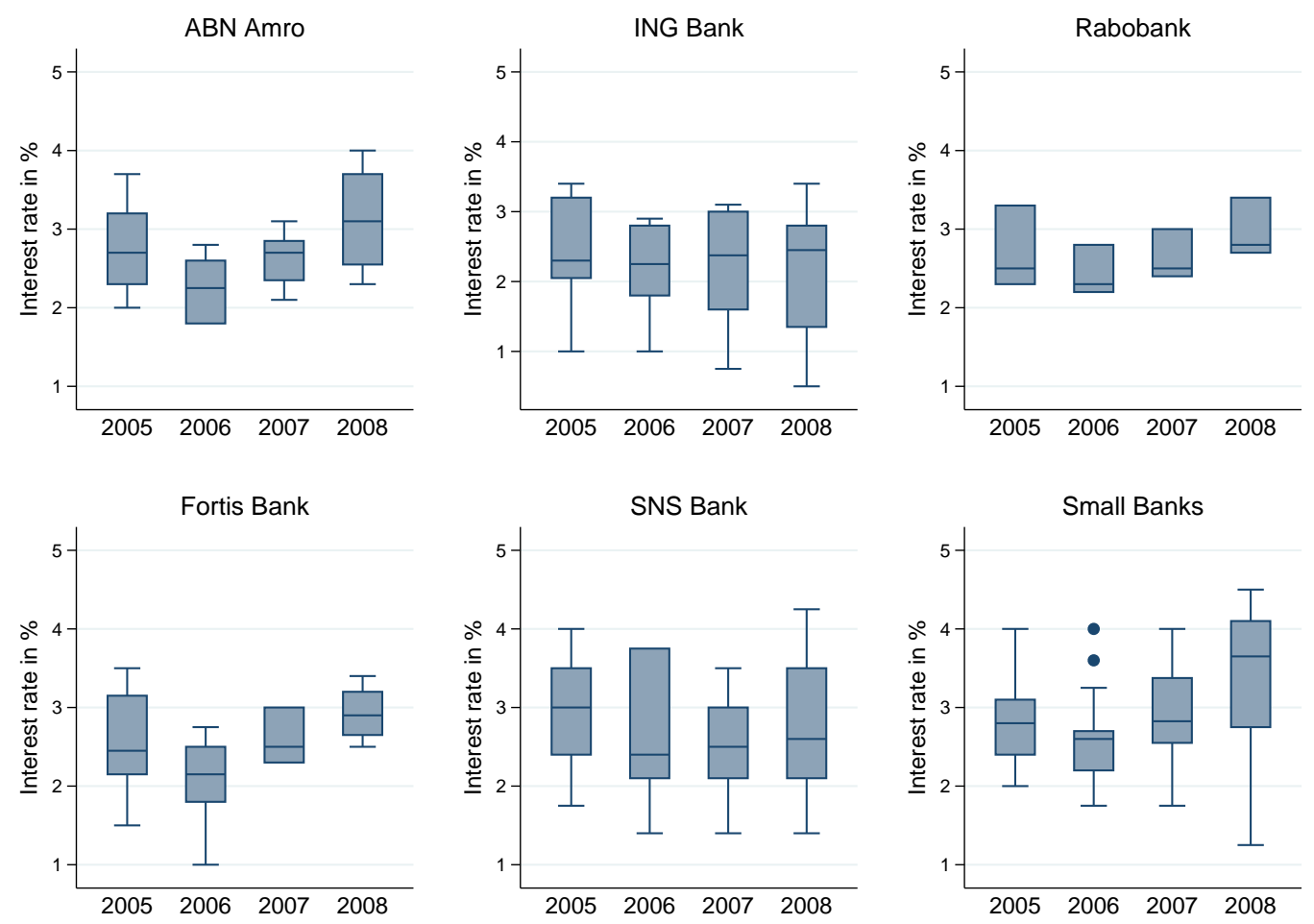

Figure 2. Distribution of interest RAtes OVER time

Note: The figure shows the distribution of annual interest rates by bank over time for all accounts used in the estimation sample. The category 'Small banks' contains all banks outside the five largest Dutch banks. Each box displays the minimum, 25\%-percentile, median, $75 \%$-percentile, and maximum in ascending order. Interest rates shown assume the respective account restrictions are fulfilled. 

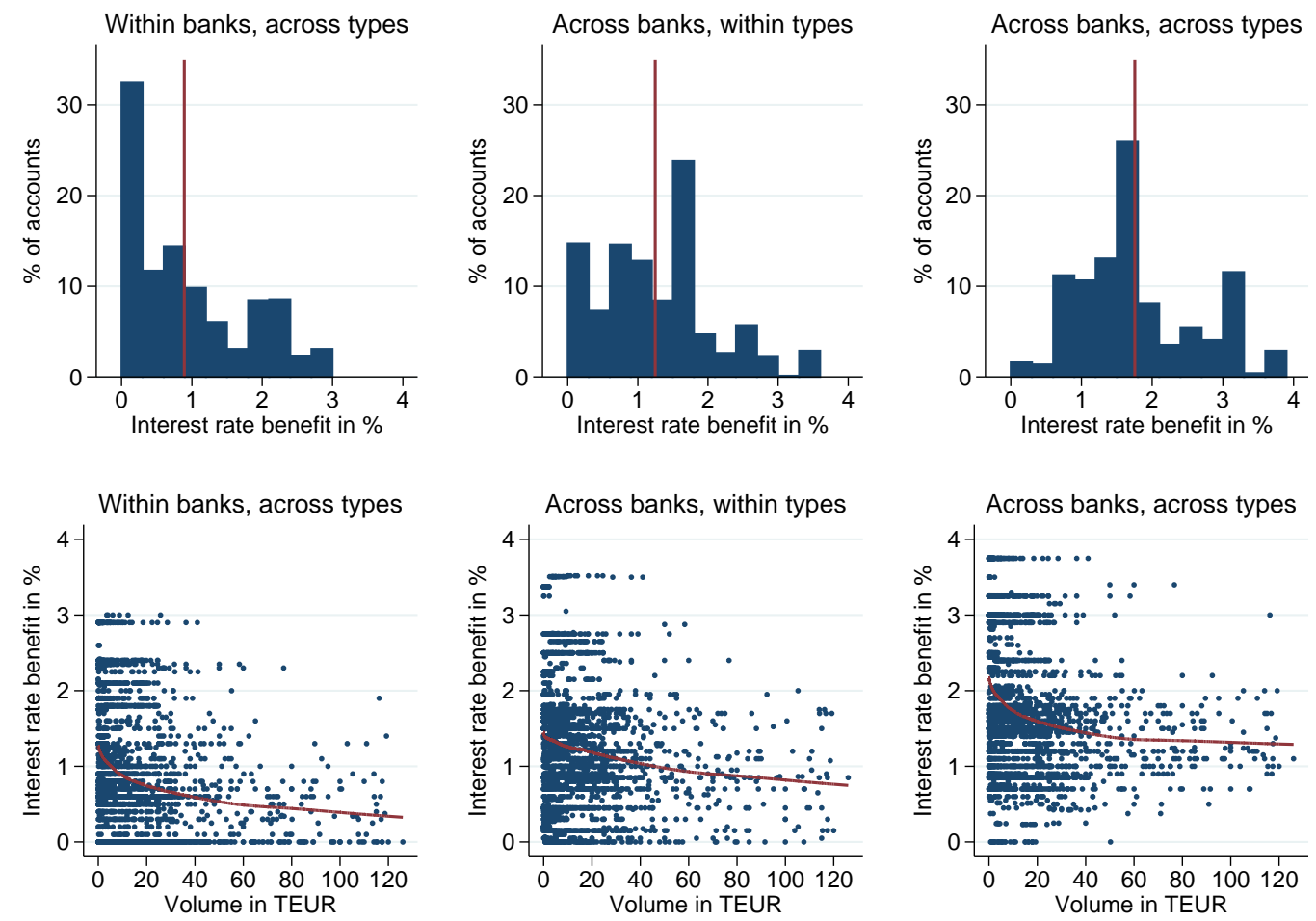

Figure 3. Distribution of interest Rate Benefits

Note: The figure shows the potential interest rate benefits from switching within the current bank, across all banks within the same account type, and across all banks and all account types. The interest rate benefit is the difference of the current rate and the highest achievable rate in each case. The upper panel shows histograms for the pooled sample where the red line indicates the mean of the distribution. The lower panel plots the benefit distribution against account volume in thousand euros. The red line shows the results of a locally weighted regression of interest rate benefits on volume using a bandwidth of 0.8 . 


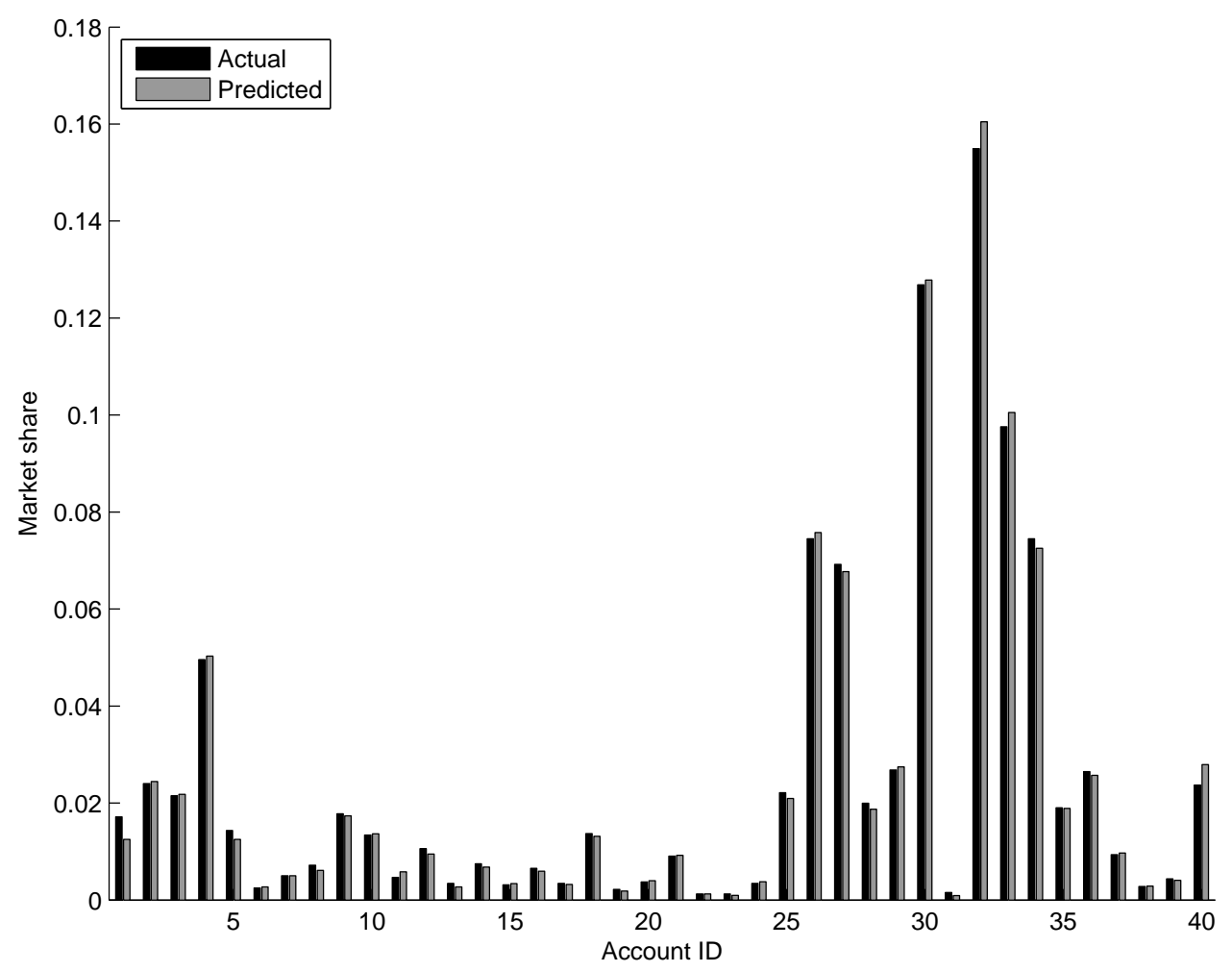

Figure 4. ACtual vs. Predicted account market shares

Note: The figure shows the model fit by comparing actual with predicted market shares for the pooled sample on account level. Predicted market shares are calculated iteratively year by year as the default option is replaced by the predicted probability for each product in the previous year. 

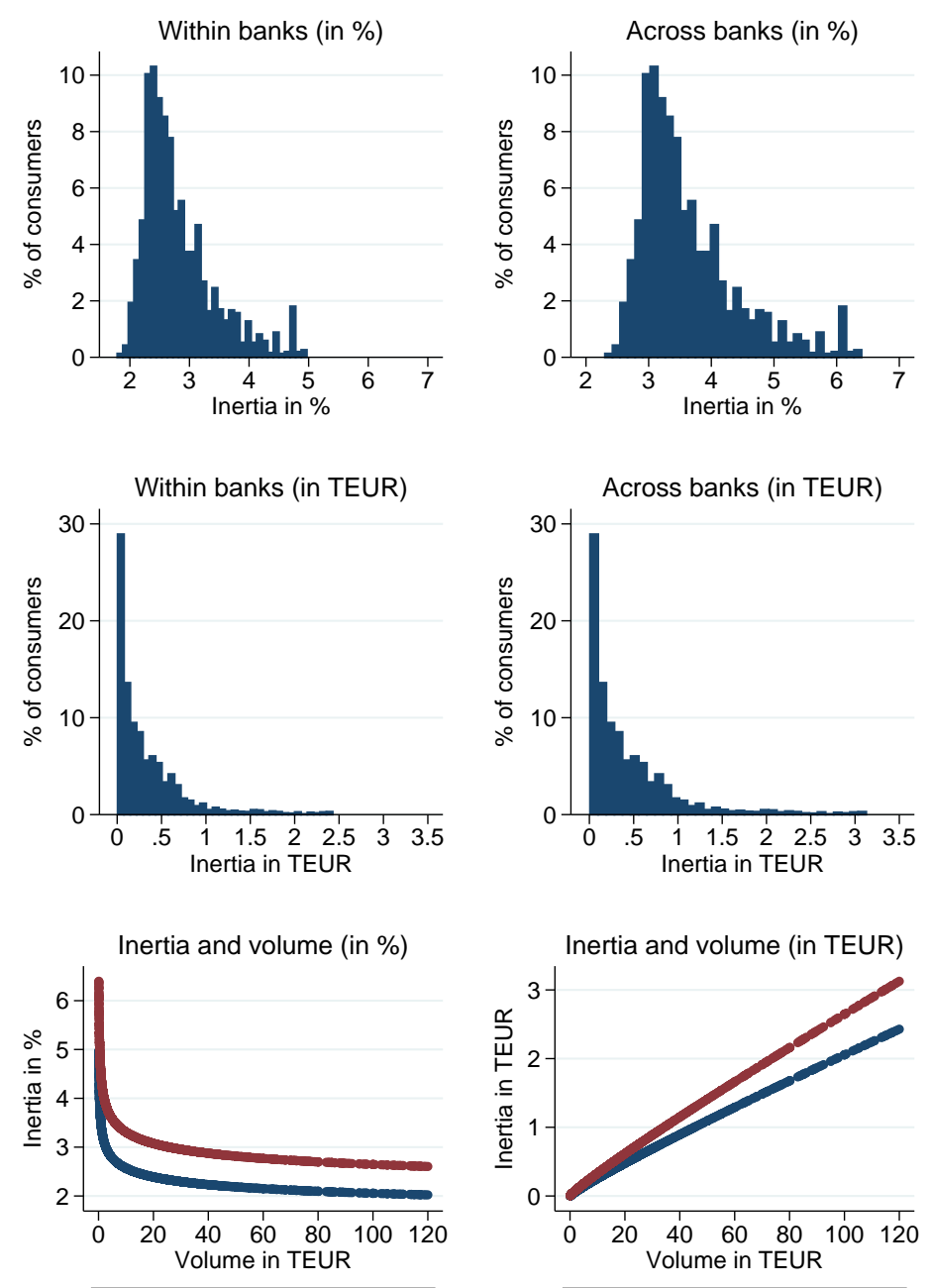

- Within banks - Across banks

- Within banks - Across banks

\begin{tabular}{lrrrrrrr}
\hline \hline & Mean & SD & p5 & p25 & p50 & p75 & p95 \\
\hline Inertia within (in \%) & 3.2 & 2.3 & 2.1 & 2.4 & 2.7 & 3.2 & 5.0 \\
Inertia across (in \%) & 4.1 & 3.0 & 2.8 & 3.1 & 3.5 & 4.1 & 6.5 \\
Inertia within (in EUR) & 360 & 560 & 10 & 60 & 180 & 460 & 1,350 \\
Inertia across (in EUR) & 460 & 720 & 10 & 70 & 230 & 590 & 1,740 \\
\hline
\end{tabular}

Figure 5. Distribution of inertia Costs

Note: The figure shows the distribution of inertia costs both within and across banks in percent of volume (upper panel), in absolute terms (middle panel), and against account volume (lowest panel). The upper panel excludes account volumes below the $5 \%$-percentile or $€ 112$. The two lower panels exclude, in addition, account volumes above the $99 \%$-percentile or $€ 126,000$ for better visual inspection. The table below reports key parameters of the distribution. 

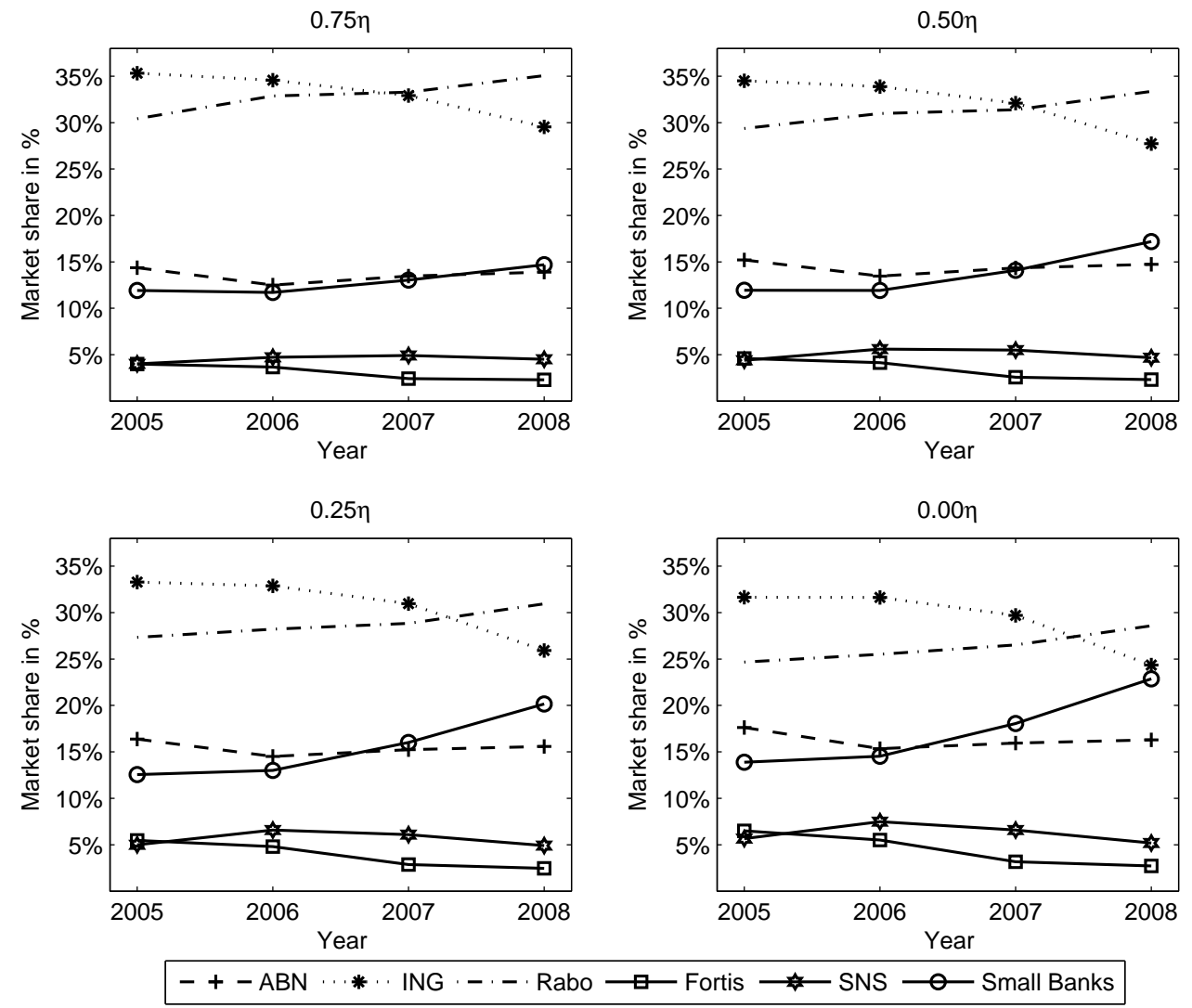

Figure 6. MARKET SHARES FOR DifFERENT LEVELS OF INERTIA

Note: The figure shows annual market shares of Dutch banks based on number of customers for different counterfactual values of inertia. The category small banks contains all banks outside the five largest Dutch banks. All counterfactuals hold prices and other factors except inertia fixed. 
TABle 1 -Descriptive Statistics

\begin{tabular}{|c|c|c|c|c|}
\hline & No switch & Within banks & Across banks & Total \\
\hline Observations & 2,793 & 201 & 2,014 & 3,208 \\
\hline Age & 51.84 & 52.56 & 54.79 & 52.09 \\
\hline Male & 0.58 & 0.57 & 0.55 & 0.57 \\
\hline Couple & 0.73 & 0.73 & 0.71 & 0.73 \\
\hline Net income in Euro & 22,367 & 26,110 & 24,119 & 22,719 \\
\hline \multicolumn{5}{|l|}{ Education } \\
\hline Less than high school & 0.27 & 0.27 & 0.25 & 0.27 \\
\hline High school & 0.32 & 0.28 & 0.22 & 0.31 \\
\hline College & 0.41 & 0.45 & 0.53 & 0.42 \\
\hline \multicolumn{5}{|l|}{ Online banking } \\
\hline No or rarely & 0.29 & 0.23 & 0.28 & 0.28 \\
\hline Often & 0.28 & 0.33 & 0.20 & 0.28 \\
\hline Very often & 0.43 & 0.44 & 0.52 & 0.44 \\
\hline \multicolumn{5}{|l|}{ Additional consumer info } \\
\hline Single account (lag) & 0.63 & 0.46 & 0.20 & 0.59 \\
\hline Single bank (lag) & 0.82 & 0.84 & 0.27 & 0.78 \\
\hline Checking account (lag) & 0.76 & 0.80 & 0.39 & 0.74 \\
\hline Mortgages (lag) & 0.20 & 0.20 & 0.11 & 0.19 \\
\hline \multicolumn{5}{|l|}{ Account characteristics } \\
\hline Interest rate & 2.27 & 2.54 & 2.76 & 2.32 \\
\hline Volume in Euro & 15,486 & 19,478 & 16,712 & 15,818 \\
\hline ABN AMRO & 0.13 & 0.15 & 0.14 & 0.13 \\
\hline ING Bank & 0.33 & 0.54 & 0.23 & 0.34 \\
\hline Rabobank & 0.35 & 0.17 & 0.20 & 0.33 \\
\hline Fortis Bank & 0.03 & 0.03 & 0.04 & 0.03 \\
\hline SNS Bank & 0.04 & 0.02 & 0.08 & 0.04 \\
\hline Small Banks & 0.11 & 0.08 & 0.31 & 0.13 \\
\hline Internet account & 0.38 & 0.54 & 0.53 & 0.40 \\
\hline Minimum amount & 0.25 & 0.15 & 0.15 & 0.24 \\
\hline Lowest balance bonus & 0.20 & 0.15 & 0.19 & 0.19 \\
\hline Balance growth bonus & 0.02 & 0.10 & 0.02 & 0.02 \\
\hline Fixed monthly deposit & 0.01 & 0.01 & 0.05 & 0.01 \\
\hline Withdrawal limitations & 0.08 & 0.03 & 0.06 & 0.07 \\
\hline Salary account & 0.03 & 0.05 & 0.03 & 0.03 \\
\hline
\end{tabular}

Note: The table shows means of main demographics and account characteristics by switching type. Single account or bank is one for individuals holding only one account or all accounts at the same bank, respectively. Checking account indicates that the first named checking account is at the main bank, while mortgage indicates any mortgage on the first and second house at the main bank. Note that both net income and online banking use contain few missing values resulting in a combined loss of 15 observations when both included in later specifications. 
Table 2-Share of Switching Accounts

\begin{tabular}{crrrr}
\hline \hline & 2005 & 2006 & 2007 & 2008 \\
\hline No switch & 86.0 & 87.6 & 87.8 & 86.8 \\
Within bank & 7.4 & 6.7 & 5.4 & 5.5 \\
Across bank & 6.5 & 5.7 & 6.8 & 7.6 \\
Total switch & 13.9 & 12.4 & 12.2 & 13.1
\end{tabular}

Note: The table shows the share of individuals switching main accounts within bank, across bank, and not at all by year. A switch is defined as a change in account name compared to the previous year. Switches due to mergers or renaming of accounts are not included. 
TABle 3-Linear PRobability MOdel of ACCOUNT SWITCHING

\begin{tabular}{lllll}
\hline \hline & \multicolumn{2}{c}{ Pooled OLS } & \multicolumn{2}{c}{ Fixed effects } \\
& Estimate & SE & Estimate & SE \\
\hline Single account (Lag) & $-0.069^{* * *}$ & 0.016 & -0.032 & 0.047 \\
Single bank (Lag) & $-0.107^{* * *}$ & 0.023 & -0.025 & 0.058 \\
Checking account (Lag) & $-0.065^{* * *}$ & 0.02 & -0.090 & 0.074 \\
Mortgage (Lag) & -0.015 & 0.015 & 0.020 & 0.043 \\
Online banking use & & & & \\
Often & $0.026^{*}$ & 0.016 & 0.028 & 0.032 \\
Very often & $0.050^{* * *}$ & 0.015 & 0.029 & 0.036 \\
Interest rate benefit & $0.027^{* * *}$ & 0.01 & $0.182^{* * *}$ & 0.026 \\
Ln(Account volume) & 0.003 & 0.003 & $0.016^{*}$ & 0.008 \\
Ln(Net income) & $0.005^{* * *}$ & 0.001 & 0.003 & 0.003 \\
Age & 0.000 & 0.000 & & \\
Male & -0.019 & 0.012 & & \\
Couple & -0.011 & 0.014 & & \\
College & 0.008 & 0.012 & & \\
Constant & $0.133^{* *}$ & 0.058 & $-0.293^{*}$ & 0.158 \\
Year fixed effects & Yes & & Yes & \\
Province fixed effects & Yes & & No & \\
Individual fixed effects & No & & Yes & \\
Bank fixed effects (Lag) & Yes & & Yes & \\
$N$ & 3,193 & & 3,193 & \\
Adjusted R2 & 0.08 & & 0.06 & \\
\hline
\end{tabular}

Note: The table shows the results from a linear probability model of account switching on a number of controls. The first two columns contain results from a pooled regression including time-invariant demographics. The last two colums include individual fixed effects but omit time-invariant demographics. Standard errors are clustered at the individual level. ${ }^{*} p<0.1 ; * * p<0.05 ;{ }^{* * *} p<0.01$ 
TABle 4 - Model estimates

\begin{tabular}{|c|c|c|c|c|c|c|}
\hline & \multicolumn{2}{|c|}{ Model (1) } & \multicolumn{2}{|c|}{ Model (2) } & \multicolumn{2}{|c|}{ Model (3) } \\
\hline & Estimate & SE & Estimate & SE & Estimate & SE \\
\hline Interest rate - $\operatorname{Ln}$ (volume) & $0.113^{* * *}$ & 0.017 & $0.116^{* * *}$ & 0.018 & $0.134^{* * *}$ & 0.019 \\
\hline Default account - base & $4.095^{* * *}$ & 0.183 & $3.703^{* * *}$ & 0.228 & $3.417^{* * *}$ & 0.250 \\
\hline Default account - net income & $-0.009^{* *}$ & 0.004 & $-0.009^{* *}$ & 0.004 & -0.008 & 0.005 \\
\hline Default account - single account & $0.713^{* * *}$ & 0.141 & $0.670^{* * *}$ & 0.143 & $0.820^{* * *}$ & 0.177 \\
\hline Default account - online banking: often & -0.220 & 0.171 & -0.198 & 0.175 & -0.302 & 0.194 \\
\hline Default account - online banking: very often & $-0.565^{* * *}$ & 0.158 & $-0.533^{* * *}$ & 0.158 & $-0.580^{* * *}$ & 0.181 \\
\hline Default account - population mean & $3.926^{* * *}$ & 0.083 & $3.465^{* * *}$ & 0.135 & $3.242^{* * *}$ & 0.157 \\
\hline Default bank - base & $0.594^{* * *}$ & 0.160 & 0.244 & 0.220 & -0.010 & 0.233 \\
\hline Default bank - single bank & $1.877^{* * *}$ & 0.196 & $1.741 * * *$ & 0.204 & $1.908^{* * *}$ & 0.221 \\
\hline Default bank - checking account & $0.595^{* * *}$ & 0.196 & $0.591^{* * *}$ & 0.203 & $0.783^{* * *}$ & 0.218 \\
\hline Default bank - mortgage & $0.429^{*}$ & 0.260 & 0.348 & 0.259 & 0.378 & 0.276 \\
\hline Default bank - population mean & $1.880^{* * *}$ & 0.103 & $1.031^{* * *}$ & 0.162 & $0.932^{* * *}$ & 0.181 \\
\hline Ln(Branches) & $0.420^{* * *}$ & 0.134 & $0.413^{* * *}$ & 0.135 & $0.431^{* * *}$ & 0.134 \\
\hline Restricted plain - male & $-0.374^{*}$ & 0.199 & $-0.392^{*}$ & 0.204 & $-0.615^{* *}$ & 0.251 \\
\hline Restricted plain - married & 0.070 & 0.223 & 0.069 & 0.228 & 0.135 & 0.269 \\
\hline Restricted plain - age & 0.005 & 0.007 & 0.004 & 0.007 & 0.001 & 0.009 \\
\hline Unrestricted internet - male & $-0.560 * * *$ & 0.199 & $-0.584^{* * *}$ & 0.199 & $-0.684^{* * *}$ & 0.235 \\
\hline Unrestricted internet - married & 0.292 & 0.231 & 0.291 & 0.229 & 0.262 & 0.258 \\
\hline Unrestricted internet - age & $-0.025^{* * *}$ & 0.008 & $-0.027 * * *$ & 0.008 & $-0.032^{* * *}$ & 0.008 \\
\hline Restricted internet - male & $-0.449^{*}$ & 0.234 & $-0.491^{* *}$ & 0.228 & $-0.583^{* *}$ & 0.251 \\
\hline Restricted internet - married & -0.058 & 0.246 & -0.054 & 0.240 & 0.014 & 0.271 \\
\hline Restricted internet - age & -0.012 & 0.008 & -0.012 & 0.008 & $-0.018^{* *}$ & 0.008 \\
\hline Control function & $-0.532^{* * *}$ & 0.177 & $-0.518^{* * *}$ & 0.177 & $-0.563^{* * *}$ & 0.201 \\
\hline Initial account & & & $0.520 * * *$ & 0.172 & $1.469^{* * *}$ & 0.244 \\
\hline Initial bank & & & $0.532^{* * *}$ & 0.206 & $0.597 * * *$ & 0.209 \\
\hline Log-likelihood & $-2,087.56$ & & $-2,068.17$ & & $-2,035.36$ & \\
\hline Account Fixed effects & yes & & yes & & yes & \\
\hline Individual random effects & no & & no & & yes & \\
\hline
\end{tabular}

Note: The table reports estimates of utility parameters not marginal effects for the primary choice model in Section VI Model (1) shows results from a conditional logit with alternative-specific intercepts. Model (2) adds initial values for account and bank defined as the first account or bank observed in the panel for each individual. Model (3) contains the full specification with individual random effects. ${ }^{*} p<0.1$; ** $p<0.05$; *** $p<0.01$ 
TABle 5 -Robustness

\begin{tabular}{|c|c|c|c|c|c|c|}
\hline & \multicolumn{2}{|c|}{ Model (1) } & \multicolumn{2}{|c|}{ Model (2) } & \multicolumn{2}{|c|}{ Model (3) } \\
\hline & Estimate & SE & Estimate & SE & Estimate & SE \\
\hline Interest rate\# $\mathrm{Ln}$ (volume) & $0.172^{* * *}$ & 0.027 & $0.142^{* * *}$ & 0.023 & $0.141^{* * *}$ & 0.019 \\
\hline Default account & $3.065^{* * *}$ & 0.205 & $3.310^{* * *}$ & 0.289 & $3.285^{* * *}$ & 0.149 \\
\hline Default bank & $1.149^{* * *}$ & 0.254 & $0.977^{* * *}$ & 0.357 & $1.006^{* * *}$ & 0.178 \\
\hline Ln(Branches) & 0.261 & 0.204 & $0.394^{* *}$ & 0.164 & $0.457^{* * *}$ & 0.128 \\
\hline Restricted Plain\#male & -0.121 & 0.368 & $-0.71^{* *}$ & 0.315 & $-0.552^{* *}$ & 0.226 \\
\hline Restricted Plain\#couple & 0.101 & 0.389 & 0.106 & 0.261 & 0.207 & 0.244 \\
\hline Restricted Plain\#age & -0.016 & 0.013 & -0.002 & 0.009 & 0.001 & 0.008 \\
\hline Unrestricted Internet\#male & $-0.582^{*}$ & 0.343 & $-0.690^{* *}$ & 0.309 & $-0.616^{* * *}$ & 0.218 \\
\hline Unrestricted Internet\#couple & 0.076 & 0.377 & 0.304 & 0.253 & 0.325 & 0.241 \\
\hline Unrestricted Internet\#age & $-0.041^{* * *}$ & 0.013 & -0.034 & 0.008 & $-0.029^{* * *}$ & 0.008 \\
\hline Restricted Internet\#male & $-0.697^{*}$ & 0.357 & -0.477 & 0.343 & $-0.532^{* *}$ & 0.227 \\
\hline Restricted Internet\#couple & 0.014 & 0.389 & 0.070 & 0.266 & 0.042 & 0.247 \\
\hline Restricted Internet\#age & $-0.024^{*}$ & 0.013 & $-0.021^{* * *}$ & 0.008 & $-0.018^{* *}$ & 0.008 \\
\hline Control function & $-0.898^{* * *}$ & 0.294 & $-0.590^{* *}$ & 0.239 & $-0.639^{* * *}$ & 0.192 \\
\hline Initial account & $1.891^{* * *}$ & 0.323 & $1.403^{*}$ & 0.731 & $1.203^{* * *}$ & 0.194 \\
\hline Initial bank & $1.172^{* * *}$ & 0.264 & 0.996 & 0.614 & $1.108^{* * *}$ & 0.184 \\
\hline Number of regions & & & & & -0.121 & 0.188 \\
\hline Total assets (in $€ \mathrm{~B}$ ) & & & & & 0.001 & 0.001 \\
\hline Core deposit ratio & & & & & -0.092 & 1.770 \\
\hline Personel expense ratio & & & & & 1.040 & 1.745 \\
\hline Log-likelihood & $-1,104.86$ & & $-1,969.44$ & & $-2,180.20$ & \\
\hline Account Fixed effects & yes & & yes & & yes & \\
\hline Individual random effects & yes & & yes & & yes & \\
\hline
\end{tabular}

Note: The table reports estimates of utility parameters not marginal effects for the primary choice model in Section VI It shows variations of the last specification in Table 4 Model (1) uses a balanced panel of consumers compared to the primary specification. Model (2) excludes consumers with volume above $€ 40 \mathrm{~T}$ and, thus, not covered by deposit insurance. Model (3) adds additional bank characteristics from Bankscope as well as the number of regions in which a bank has a branch presence. ${ }^{*} p<0.1$; ${ }^{* *} p<0.05$; *** $p<0.01$ 
TABle 6 - OLS of interest Rate on account age

\begin{tabular}{lllllll}
\hline \hline & \multicolumn{2}{c}{1,000 Euro } & \multicolumn{2}{c}{10,000 Euro } & \multicolumn{2}{c}{50,000 Euro } \\
& Estimate & SE & Estimate & SE & Estimate & SE \\
\hline Acc. age since 2001 & & & & & & \\
1 & 0.261 & 0.195 & 0.092 & 0.169 & 0.025 & 0.144 \\
2 & 0.027 & 0.189 & -0.057 & 0.182 & -0.063 & 0.172 \\
3 & -0.07 & 0.179 & -0.107 & 0.165 & -0.129 & 0.161 \\
4 & $-0.260^{*}$ & 0.151 & $-0.461^{* * *}$ & 0.139 & $-0.403^{* * *}$ & 0.126 \\
5 & $-0.439^{* *}$ & 0.172 & $-0.635^{* * *}$ & 0.153 & $-0.568^{* * *}$ & 0.139 \\
6 & $-0.534^{* * *}$ & 0.192 & $-0.801^{* * *}$ & 0.178 & $-0.713^{* * *}$ & 0.161 \\
7 & $-0.867^{* * *}$ & 0.24 & $-1.097^{* * *}$ & 0.23 & $-0.955^{* * *}$ & 0.216 \\
Bank FE & & & & & & \\
ABN AMRO & -0.137 & 0.152 & $-0.352^{* *}$ & 0.16 & $-0.227^{*}$ & 0.117 \\
ING Bank & $-0.949^{* * *}$ & 0.205 & $-0.716^{* * *}$ & 0.219 & $-0.788^{* * *}$ & 0.204 \\
Rabobank & -0.195 & 0.225 & -0.166 & 0.223 & -0.276 & 0.197 \\
Fortis Bank & $-0.693^{* * *}$ & 0.211 & $-0.409^{* *}$ & 0.199 & $-0.510^{* * *}$ & 0.181 \\
SNS Bank & $-0.326^{* *}$ & 0.133 & $-0.281^{*}$ & 0.148 & $-0.335^{* *}$ & 0.158 \\
Constant & $2.882^{* * *}$ & 0.152 & $3.019^{* * *}$ & 0.142 & $2.992^{* * *}$ & 0.136 \\
Account restrictions & Yes & & Yes & & Yes & \\
Year FE & Yes & & Yes & & Yes & \\
$N$ & 242 & & 251 & & 253 & \\
Adjusted R-squared & 0.71 & & 0.57 & & 0.57 & \\
\hline
\end{tabular}

Note: The table reports OLS estimates from a regression of account interest rate on account age and other controls for three different volumes $(€ 1,000, € 10,000$, and $€ 50,000)$. Account age is the number of years an account has appeared in the DNB Household Survey since the year 2001. The unit of observation is an account in a given year. Standard errors are clustered at the account level. ${ }^{*} p<0.1$ * $^{* *} p<0.05 ;{ }^{* * *} p<0.01$ 
TABle 7-CONSUMER SURPlus IMPACT OF COUNTERFACTUAL INERTIA

\begin{tabular}{lrrrrr}
\hline \hline & $0.75 \eta$ & $0.50 \eta$ & $0.25 \eta$ & $0.00 \eta$ & $\eta^{A}=0$ \\
\hline Population mean & 98 & 177 & 234 & 272 & 98 \\
& $(0.87)$ & $(1.58)$ & $(2.09)$ & $(2.43)$ & $(0.80)$ \\
Population median & 48 & 85 & 112 & 128 & 36 \\
& $(0.75)$ & $(1.37)$ & $(1.82)$ & $(2.11)$ & $(0.75)$ \\
Volume quartile 1 & 5 & 10 & 13 & 15 & 5 \\
& $(1.45)$ & $(2.65)$ & $(3.53)$ & $(4.13)$ & $(1.17)$ \\
Volume quartile 2 & 27 & 49 & 65 & 75 & 25 \\
& $(0.80)$ & $(1.44)$ & $(1.90)$ & $(2.21)$ & $(0.75)$ \\
Volume quartile 3 & 78 & 139 & 183 & 212 & 79 \\
& $(0.68)$ & $(1.22)$ & $(1.61)$ & $(1.87)$ & $(0.68)$ \\
Volume quartile 4 & 267 & 483 & 640 & 743 & 268 \\
& $(0.60)$ & $(1.09)$ & $(1.45)$ & $(1.68)$ & $(0.63)$ \\
Single & 85 & 153 & 202 & 234 & 90 \\
Couple & $(0.96)$ & $(1.74)$ & $(2.29)$ & $(2.66)$ & $(0.88)$ \\
Female & 103 & 186 & 247 & 287 & 101 \\
& $(0.83)$ & $(1.52)$ & $(2.01)$ & $(2.35)$ & $(0.77)$ \\
Male & 78 & 142 & 190 & 222 & 74 \\
Age <30 & $(0.87)$ & $(1.57)$ & $(2.08)$ & $(2.43)$ & $(0.79)$ \\
& 113 & 203 & 268 & 310 & 116 \\
Age 30-50 & $(0.87)$ & $(1.58)$ & $(2.10)$ & $(2.44)$ & $(0.81)$ \\
& 37 & 68 & 92 & 109 & 27 \\
Age 50-65 & $(1.07)$ & $(1.98)$ & $(2.66)$ & $(3.14)$ & $(0.76)$ \\
Age $>65$ & 73 & 132 & 175 & 204 & 67 \\
& $(0.92)$ & $(1.67)$ & $(2.23)$ & $(2.60)$ & $(0.81)$ \\
& 120 & 216 & 285 & 331 & 123 \\
Note: & $(0.83)$ & $(1.49)$ & $(1.97)$ & $(2.28)$ & $(0.81)$ \\
& 132 & 238 & 313 & 362 & 140 \\
& $(0.77)$ & $(1.40)$ & $(1.84)$ & $(2.12)$ & $(0.77)$ \\
\hline
\end{tabular}

Note: The table shows consumer surplus changes for the mean and median consumer as well as specific subgroups relative to the baseline preferences in Table 4 In counterfactual 1 (first four columns), overall inertia is reduced by a factor $z$. In counterfactual 2 (last column), inertia within bank is eliminated holding inertia across bank fixed. Relative surplus changes are reported in brackets. All simulations hold prices and other factors except inertia fixed. 
Appendix A: Additional Descriptives

TABle A1-Summary STATistics ON BANK-LEvel

\begin{tabular}{|c|c|c|c|c|c|c|c|c|}
\hline & \multicolumn{4}{|c|}{ Number of accounts } & \multicolumn{4}{|c|}{ Market share by enrollment } \\
\hline & 2005 & 2006 & 2007 & 2008 & 2005 & 2006 & 2007 & 2008 \\
\hline ABN Amro & 8 & 7 & 6 & 8 & 0.13 & 0.14 & 0.13 & 0.12 \\
\hline ING Bank & 10 & 11 & 11 & 12 & 0.35 & 0.33 & 0.34 & 0.34 \\
\hline Rabobank & 3 & 3 & 3 & 3 & 0.28 & 0.28 & 0.27 & 0.27 \\
\hline Fortis Bank & 6 & 6 & 4 & 4 & 0.04 & 0.04 & 0.04 & 0.04 \\
\hline SNS Bank & 17 & 18 & 20 & 20 & 0.05 & 0.05 & 0.06 & 0.06 \\
\hline Small Banks & 3 & 3 & 3 & 3 & 0.15 & 0.16 & 0.16 & 0.17 \\
\hline
\end{tabular}

Note: The left panel reports the total number of accounts offered based on the interest rate data set. 'Small Banks' contains the median number of accounts in that category. The right panel reports the market share based on number of accounts according to the unrestricted DHS data. See Section III for a detailed description of both data sources. 
TABle A2-SAMPle COMPARison

\begin{tabular}{lrrr}
\hline \hline & All accounts & Main account & Final sample \\
\hline Observations & 8,775 & 5,400 & 3,208 \\
Age & 51.05 & 50.29 & 52.13 \\
Male & 0.56 & 0.55 & 0.57 \\
Couple & 0.75 & 0.74 & 0.73 \\
Number of Children & 0.69 & 0.69 & 0.64 \\
Education & & & \\
Less than highschool & 0.25 & 0.27 & 0.27 \\
High school & 0.31 & 0.32 & 0.31 \\
College & 0.44 & 0.41 & 0.43 \\
Account characteristics & & & \\
ABN AMRO & 0.13 & 0.14 & 0.13 \\
ING Bank & 0.34 & 0.30 & 0.34 \\
Rabobank & 0.27 & 0.32 & 0.33 \\
Fortis Bank & 0.04 & 0.04 & 0.03 \\
SNS Bank & 0.05 & 0.05 & 0.04 \\
Small Banks & 0.16 & 0.14 & 0.13 \\
Amount in $€$ & 10,700 & 14,356 & 15,860
\end{tabular}

Note: The table shows summary statistics of main demographics and account characteristics. All accounts contains all savings accounts held by households in the DHS. Main accounts contains the sample of accounts with the highest volume held by each individual in the sample for a given year. Final sample includes all accounts with matched interest rate observed at least two consecutive periods. 
Table A3-Optional vs. Forced Choosers

\begin{tabular}{lrr}
\hline \hline & Optional & Forced \\
\hline Age & 52.08 & 49.96 \\
Male & 0.57 & 0.54 \\
Couple & 0.73 & 0.84 \\
Net income in Euro & 22,697 & 21,303 \\
Less than highschool & 0.27 & 0.36 \\
High school & 0.31 & 0.41 \\
College & 0.42 & 0.23 \\
No or rarely & 0.28 & 0.4 \\
Often & 0.28 & 0.24 \\
Very often & 0.44 & 0.36 \\
Volume in Euro & 15,863 & 11,880 \\
N & 3,192 & 180 \\
\hline Note: The table shows descriptive statistics for the full \\
sample for forced and optional choosers. Forced choosers \\
have either just entered the market or their previous bank \\
or account was discontinued. They, thus, choose without \\
inertia compared to optional choosers with an existing \\
default option.
\end{tabular}




\section{Appendix B: Data Processing}

Whereas the majority of survey respondents provide a bank name, the data on the names of savings accounts contain some typos, abbreviations, and few inconsistencies. I process this raw information in the DHS in the following way. Using the bank and account names from the market interest rate data as a reference for the correct spelling, I replace all incorrectly spelled names and abbreviations in the DHS by their proper name. I replace those cases in which participants report outdated names of accounts by the names of their successor accounts. Finally, I set all potential inconsistent cases to missing 70

As I later match the DHS and market data based on volume as well, I also recover those cases with unreported individual account volume following the procedure used by the official provider of the DHS (CentERdata). CentERdata first recovers volumes for individual savings accounts (details follow) and then aggregates over all accounts of each household member yielding total savings volume per household member (i.e., at the individual level). Only the recovered volume of the latter is available in the public version of the dataset. However, I am able to recover the large majority of the inserted values for individual savings accounts by following the same process that CentERdata has applied to calculate total savings account volume per household member.71 First, if a respondent does not report the exact amount of a savings account, the respondent is asked to choose from a sequence of follow-up questions in the form of unfolding brackets. In this case, I use the mid-point of the bracketed answer or the lower bound in case of the highest open-ended category ( $€ 25,000$ or more). This leaves $10.3 \%$ of accounts with missing volume. Second, for these missing cases, I use the average amount of this savings account over the last two years. This leaves $8.1 \%$ of accounts with missing volume. For the remaining individual household members with at least one account with unreported volume, an imputed value for total savings volume was used by CentERdata. This was derived from a regression of total savings volume on a large set of individual characteristics. I use this imputed value to recover the volume of individual savings accounts in the following way. If only one account of a household member is left with missing volume, I use the difference between the total savings volume and the sum of all reported account volumes of that individual to fill in the single missing volume. ${ }^{72}$ This still leaves few individual household members with more than one account with missing volume. For those household members, I distribute this difference equally across all

\footnotetext{
${ }^{70}$ For example, some respondents report accounts not offered by the reported bank in a specific year.

${ }^{71}$ Details can be found in the documentation of the DHS 2005 wave (available at: http://cdata3.uvt.nl/dhs/files/CodebookWave2005English.pdf)

${ }^{\top 2} 60 \%$ of those household members hold only one account and thus total volume and individual account volume are equivalent.
} 
savings accounts with remaining missing volume ${ }^{73}$

\section{Appendix C: Estimation procedure}

This section lays out the specific estimation procedure for the model described above. I estimate a random coefficient model using simulated maximum likelihood techniques as described in Train (2009). As I use panel data, I model the probability of observing a sequence of choices for each depositor. The choice probability of depositor $i$ choosing a savings account $j$ for the sequence $t=1, \ldots, T$ is given by:

$$
P_{i j}=\int \prod_{t=1}^{T} P_{i j t}(\mathbf{a}) d \Phi(\mathbf{a} \mid \theta)
$$

where $\Phi(\mathbf{a} \mid \theta)$ denotes the multivariate normal distribution of the random coefficients and $\theta$ are the parameters of this distribution I want to estimate. The choice probability for a given year conditional on the parameter vector $\mathbf{a}$ as used above is given by:

$$
P_{i j t}=\frac{e^{V_{i j t}\left(a_{i j}, p_{i j t}, n_{i j t}, \mathbf{y}_{\mathbf{i j}, \mathbf{t}-\mathbf{1}}, \alpha\left(\Lambda_{i t}\right), \gamma, \eta\right)}}{1+\sum_{j=1}^{J} e^{V_{i j t}\left(a_{i j}, p_{i j t}, n_{i j t}, \mathbf{y}_{\mathbf{i j}, \mathbf{t}-\mathbf{1}}, \alpha\left(\Lambda_{i t}\right), \gamma, \eta\right)}}
$$

The above likelihood has no closed-form analytical solution and, thus, has to be approximated by simulation. Let us index a draw by $r=1, . ., R$ where $R$ denotes the total number of draws. Then the simulation procedure works as follows. For each consumer, I first take a draw for the vector $\mathbf{a}^{r}$ from the distribution $\Phi(\mathbf{a} \mid \theta)$. For each specific draw, I calculate the logit probability for each period, and then take the product of these probabilities. This procedure is repeated for the total number of draws. The resulting choice probabilities are then averaged resulting in the simulated probability of observing a sequence of choices:

$$
\hat{P}_{i j}=\frac{1}{R} \sum_{r=1}^{R} P_{i j}\left(\mathbf{a}^{r}\right)
$$

which is an unbiased estimator of the true choice probability $P_{i j}$ summing to one over all alternatives. One can now construct the simulated log-likelihood (SLL) by inserting

\footnotetext{
${ }^{73}$ Note that in the last two cases, I only consider accounts that do not exceed the total number of accounts as originally stated by the respondent, for example, I only consider the first three reported accounts of a household that claims to have 3 accounts in total but reports four. The same approach is used in the DHS for the calculation of total savings wealth.
} 
the simulated probabilities into the log-likelihood function:

$$
S L L(\theta)=\sum_{i=1}^{I} \sum_{j=1}^{J} y_{i j} \ln \hat{P}_{i j}
$$

where $y_{i j}$ is an indicator function which is one for the actual sequence of choices made by individual $i$. The maximum likelihood estimator now finds the parameter vector $\theta$ that maximizes $S S L(\theta)$. More precisely, starting from an initial parameter guess $\theta_{0}$, in each iteration step the algorithm moves to a new parameter vector where $S S L(\theta)$ is higher than in the previous step until a specified convergence criterion is reached. In the results presented in the paper, I choose $R=200$ Halton draws for each consumer.

\section{Appendix D: Initial CONDITIONS}

In this appendix, I show how the logic in Wooldridge (2005) shown for binary and ordered choice models extends to the unordered multinomial case with more than two products. The paper applies to cases, where the initial condition of the choice process is unknown as is the case in this work. Instead of simulating the distribution of the initial condition which is often imperfect, he suggests to control for unobserved persistent heterogeneity correlated with the initial condition by modeling the choice probabilities conditional on the initial choices. I start by defining the general indirect utility from product $j$ by:

$$
V_{i j t}=\mathbf{x}_{\mathbf{i j t}}^{\prime} \beta+\eta y_{i j, t-1}+\alpha_{i j}+\epsilon_{i j t}
$$

where $\mathbf{x}_{\mathbf{i j t}}^{\prime}$ is a set of time-varying product characteristics potentially varying over consumers, $y_{i j, t-1}$ is the lagged dependent variable taking the value 1 if consumer $i$ chooses product $j$ in $t-1, \alpha_{i j}$ is an unobserved individual-product-specific factor, and $\epsilon_{i j t}$ is an i.i.d. type 1 extreme value distributed error term. The probability that consumer $i$ chooses product $j$ in year $t$ is given by:

$$
P_{i j t}=\Lambda\left(\mathbf{x}_{\mathbf{i j t}}^{\prime} \beta+\eta y_{i j, t-1}+\alpha_{i j}\right)=\frac{e^{\mathbf{x}_{\mathbf{i j t}}^{\prime} \beta+\eta y_{i j, t-1}+\alpha_{i j}}}{\sum_{j=0}^{J_{t}} e^{\mathbf{x}_{\mathbf{i j t}}^{\prime} \beta+\eta y_{i j, t-1}+\alpha_{i j}}}
$$

Aggregation of the choice probabilities over products and time yields the probability of observing a sequence of choices for consumer $i$ : 


$$
P_{i}=\prod_{t=1}^{T} \prod_{j=0}^{J} \Lambda\left(\mathbf{x}_{\mathbf{i j t}}^{\prime} \beta+\eta y_{i j, t-1}+\alpha_{i j}\right)^{y_{i j t}}
$$

which reduces to the simple logit formula for the case of $J=2$. Adjusting the approach of Wooldridge (2005) for binary choice models to multinomial models with more than two alternatives, I model the distribution of the unobserved component conditional on the initial values as follows:

$$
\alpha_{i j}=\alpha_{j}+\gamma y_{i j 0}+{\overline{\mathbf{x}_{\mathbf{i j}}}}^{\prime} \delta+a_{i j}, \quad \text { with } a_{i j} \mid\left(y_{i j 0},{\overline{\mathbf{x}_{\mathbf{i j}}}}^{\prime}\right) \sim N\left(0, \sigma_{a}^{2}\right)
$$

Thus, in contrast to his paper, there is now an additional dimension of variability due to the existence of many products. The unobserved component now depends on a product-specific intercept term, the initial choice, the individual time averages over all time-varying covariates, and a mean-zero random effect. Plugging in yields a logit model with response probability:

$$
P_{i j t}=\Lambda\left(\mathbf{x}_{\mathbf{i j t}}^{\prime} \beta+\eta y_{i j, t-1}+\alpha_{j}+\gamma y_{i j 0}+\overline{\mathbf{x}}_{\mathbf{i j}}^{\prime} \delta+a_{i j}\right)
$$

Integrating over the normally distributed random effects $a_{i j}$ from $P_{i}$ and as before aggregating over products and time yields:

$$
P_{i}=\int_{a_{0}, \ldots, a_{J}} \prod_{t=1}^{T} \prod_{j=0}^{J} \Lambda\left(\mathbf{x}_{\mathbf{i j \mathbf { t }}}^{\prime} \beta+\eta y_{i j, t-1}+\alpha_{j}+\gamma y_{i j 0}+{\overline{\mathbf{x}_{\mathbf{i j}}}}^{\prime} \delta+a_{i j}\right)^{y_{i j t}} d \Phi\left(a_{0}\right) \ldots d \Phi\left(a_{J}\right)
$$

which has the same structure as a mixed logit of sequential choice as, for instance, described in Train (2009). Thus, the logic in Wooldridge (2005) shown for dynamic binary and ordered probit, tobit and poisson models, extends to models of unordered choice, in particular the conditional logit model with the difference that now there is no closed form solution for the likelihood so the model needs to be estimated by simulation.

Appendix E: Questions Used

\section{Account Characteristics}

1 Minimum amount: Minimum amount required to earn full interest rate

2 Lowest balance bonus: Balance may not fall below specified amount threshold during 
calendar year/quarter to earn full rate

3 Balance growth bonus: Balance needs to grow by specified amount per calendar year/quarter

4 Limited withdrawal: Maximum withdrawal per month

5 Additional fees: withdrawal / account fees

6 Salary account: Salary account required at the same bank

7 Internet account: Account is fully managed online

\section{Account Name}

Can you describe what kind of account it is (e.g. a 'GroeiGemak Spaarrekening', a 'Bonus Spaarrekening' with ABN AMRO, a 'Plusrekening' or a 'Kapitaalrekening' with the Postbank, or a 'Rabo Rendement Rekening')?

any answer ...

\section{Account Volume}

What was the balance of your [1st thru 7 th] account on 31 December 2004 ?

1 amount: ..., 2 don't know

\section{Age}

Year of birth of the respondent

any answer ...

\section{Bank information}

\section{Savings accounts}

With which bank or financial institution is your [1st thru 7 th] account registered?

1 ABN AMRO, 2 Postbank, 3 Rabobank, 4 ING Bank, 5 Fortis Bank, 6 SNS Bank, 7 other

\section{Checking accounts}

With which bank or financial institution is your [1st thru 5th] account registered?

1 ABN AMRO, 2 Postbank, 3 Rabobank, 4 ING Bank, 5 Fortis Bank, 6 SNS Bank, 7 other

\section{Mortgages}

With which financial institution have you taken out the [1st thru 5th] mortgage? 1 ABN AMRO, 2 Postbank, 3 Rabobank, 4 ING Bank, 5 Fortis Bank, 6 SNS Bank, 7 Nationale Nederlanden, 8 AEGON, 9 AMEV, 10 Bouwfonds Nederlandse Gemeenten, 11 ABP, 12 Other financial institution 
Note: I group ING and Postbank together as the former mainly operates through the latter in the market for savings accounts. In case of 'other', respondents are asked to name the exact name of the bank. Bank information for mortgages is asked for the first and second residential house.

\section{Couple}

Is there a partner present in the household?

0 no, 1 yes

\section{Education}

Highest level of education completed

1 (continued) special education

2 kindergarten/primary education

$3 \mathrm{VMBO}$ (pre-vocational education)

4 HAVO, VWO (pre-university education)

5 senior vocational training or training through apprentice system

6 vocational colleges

7 university education

8 no education (yet)

9 other sort of education/training

Note: I group categories 6 and 7 into college and 4 and 5 into high school. The remaining categories constitute the base.

\section{Online banking use}

Nowadays, a number of banks offer the possibility to arrange banking affairs through Internet, without the mediation of a person. Examples of such a facility are: HomeNet, Internet banking or Girotel. Do you use such a facility?

1 no, 2 yes, very rarely, 3 yes, every now and then, 4 yes, often, 5 yes, very often, 6 I don't know

Note: I group the first three categories together due to few observations in category 2 and 3 and no significant differences across these categories in the estimation specification.

\section{Net Income}

Equal to the derived net income on individual level as provided by CentER in the aggregated data on income.

Note: In contrast to the DHS which counts net income as missing if one of the sub components is missing, I count net income as missing only if all asset subcomponents 
are missing. I also use information from previous years within the same individual to reduce the number of missing values. Both variables are highly similar in terms of distributional aspects, since often only small subcomponents are not reported.

\section{Province}

1 Groningen, 2 Friesland, 3 Drenthe, 4 Overijssel, 5 Flevoland, 6 Gelderland, 7 Utrecht, 8 Noord-Holland, 9 Zuid-Holland, 10 Zeeland, 11 Noord-Brabant, 12 Limburg

\section{Sex}

1 male, 2 female 


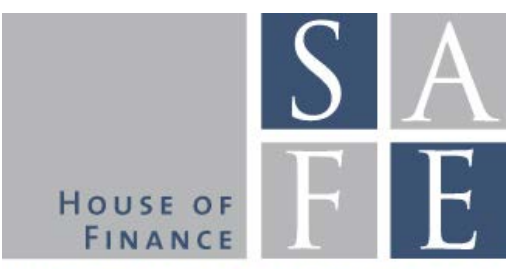

WORKING PAPER SERIES

\section{Recent Issues}

No. 222 Vanessa Endrejat, Matthias

Thiemann

No. 221 Axel H. Börsch-Supan, Klaus Härtl, Duarte N. Leite, Alexander Ludwig

No. 220 Yangming Bao, Martin R. Goetz

No. 219 Andreas Hackethal - Christine Laudenbach - Steffen Meyer Annika Weber

No. 218 Florian Hoffmann, Roman Inderst, Marcus Opp

No. 217 Maddalena Davoli, Jia Hou

No. 216 Stefano Colonnello, Giuliano Curatola, Alessandro Gioffré

No. 215 Zsuzsa R. Huszár, Zorka Simon

No. 214 Edin Ibrocevic, Matthias Thiemann

No. 213 Klaus Gugler, Michael Weichselbaumer, Christine Zulehner

No. 212 Henning Hesse

No. 211 Thomas Mosk
Reviving the Shadow Banking Chain in Europe: Regulatory Agency, Technical Complexity and the Dynamics of CoHabitation

Endogenous Retirement Behavior of Heterogeneous Households Under Pension Reforms

Local Peer Effects and Corporate Investment

Client Involvement in Expert Advice Antibiotics in Finance?

Only Time will Tell: A Theory of Deferred Compensation

Financial Literacy and Socialist Education: Lessons from the German Reunification

Pricing Sin Stocks: Ethical Preference vs. Risk Aversion

The Pricing Implications of the Oligopolistic Securities Lending Market: A Beneficial Owner Perspective

All Economic Ideas are Equal, but Some are more Equal than Others: A Differentiated Perspective on Macroprudential Ideas and their Implementation

Effects of Government Spending on Employment: Evidence from Winners and Runners-up in Procurement Auctions

Incentive Effects from Write-down CoCo Bonds: An Empirical Analysis

Bargaining with a Bank 